(D) Check for updates

Cite this: Dalton Trans., 2017, 46, 9969

Received 27th April 2017 Accepted 12th July 2017

DOI: $10.1039 / \mathrm{c} 7 \mathrm{dt01540b}$

rsc.li/dalton

\section{Frontier orbitals of photosubstitutionally active ruthenium complexes: an experimental study of the spectator ligands' electronic properties influence on photoreactivity $\dagger$}

\author{
Hyo Jin Jang, ${ }^{a}$ Samantha L. Hopkins, (D) a Maxime A. Siegler ${ }^{\mathrm{b}}$ and \\ Sylvestre Bonnet (D) *a
}

\begin{abstract}
The synthesis and characterization of $\left[R u(t p y)\left(R_{2} b p y\right)(L)\right](X)_{n}$ complexes (tpy $=2,2^{\prime}: 6^{\prime}, 2^{\prime \prime}$-terpyridine, $R_{2} b p y=$ 4,4'-dimethyl-2,2'-bipyridine (dmbpy), or 4,4'-bis(trifluoromethyl)-2,2'-bipyridine (tfmbpy), $\mathrm{X}=\mathrm{Cl}^{-}$or $\mathrm{PF}_{6}{ }^{-}$, and $n=1$ or 2 ) are described. The dmbpy and tfmbpy bidentate ligands allow for investigating the effects of electron-donating and electron-withdrawing ligands, respectively, on the frontier orbital energetics as well as the photoreactivity of these ruthenium polypyridyl complexes for five prototypical monodentate ligands $\mathrm{L}=\mathrm{Cl}^{-}, \mathrm{H}_{2} \mathrm{O}, \mathrm{CH}_{3} \mathrm{CN}, 2$-(methylthio)ethanol (Hmte), or pyridine. According to spectroscopic and electrochemical studies, the dmbpy analogues displayed a singlet metal-to-ligand charge transfer $\left({ }^{1} \mathrm{MLCT}\right)$ transition at higher energy than the tfmbpy analogues. The shift of the ${ }^{1} \mathrm{MLCT}$ to higher energy results from the lowest unoccupied molecular orbital (LUMO) for the dmbpy analogues being tpy-based, whereas for the tfmbpy analogues orbital inversion occurs resulting in a tfmbpy-based LUMO. The energy level of the highest occupied molecular orbital (HOMO) was considerably affected by the nature of the monodentate ligand. Visible light irradiation of the complexes demonstrated that the tfmbpy analogue increased the rate and quantum yields of photosubstitution reactions, compared to the dmbpy analogue, suggesting that the electron-withdrawing substituents allowed better thermal accessibility of the triplet metal-centered $\left({ }^{3} \mathrm{MC}\right)$ state from the photochemically generated triplet metal-toligand charge transfer ( ${ }^{3} \mathrm{MLCT}$ ) excited state. A correlation between the photolability of the monodentate ligands and the electrochemical reversibility of the metal-based oxidation is also reported.
\end{abstract}

Over the past several decades, ruthenium photochemistry has been studied for various applications including dye-sensitized solar cells, ${ }^{1}$ energy storage, ${ }^{2}$ photochemical synthesis, ${ }^{3}$ water oxidation catalysis, ${ }^{4}$ or nitric oxide delivery to biological targets. ${ }^{5}$ Additionally, ruthenium polypyridyl complexes have received significant attention as light-activated anti-cancer drugs because they can undergo ligand photosubstitution, which sometimes results in an "activated" ruthenium species that is more cytotoxic than the non-irradiated precursor. ${ }^{6-12}$ Photosubstitution reactions occur under visible light irradiation because of the unique excited state properties of

\footnotetext{
${ }^{a}$ Leiden Institute of Chemistry, Leiden University, Einsteinweg 55, 2300 RA Leiden, The Netherlands. E-mail: bonnet@chem.leidenuniv.nl

${ }^{b}$ Small Molecule X-ray Facility, Department of Chemistry, Johns Hopkins University, Baltimore, Maryland 21218, USA

$\dagger$ Electronic supplementary information (ESI) available: Ligand synthesis and characterization, complex/photoproduct characterization and crystal structures. CCDC 1544943-1544950. For ESI and crystallographic data in CIF or other electronic format see DOI: $10.1039 / \mathrm{c} 7 \mathrm{dt} 01540 \mathrm{~b}$
}

ruthenium polypyridyl complexes. Upon visible light irradiation, Ru-based complexes display low energy metal-toligand charge transfer $\left({ }^{1} \mathrm{MLCT}\right)$ transitions, which are the result of an electron being excited from the $\mathrm{Ru}(\mathrm{d} \pi)$-based highest occupied molecular orbital (HOMO) to a ligand( $\left(\pi^{*}\right)$ based lowest unoccupied molecular orbital (LUMO). The ${ }^{1}$ MLCT excited state then undergoes rapid intersystem crossing to the ${ }^{3}$ MLCT excited state, from which triplet metal-centered $\left({ }^{3} \mathrm{MC}\right)$ states are thermally accessible. Such ${ }^{3} \mathrm{MC}$ states are ligand field excited states where an electron is excited from the $t_{2 g}$ to $e_{g}$ orbital, resulting in ligand dissociation due to the anti-bonding character of the $\mathrm{e}_{\mathrm{g}}$ orbital. ${ }^{13,14} \mathrm{~A}$ number of studies have been performed that have increased our understanding of the relationship between the photoreactivity of ruthenium polypyridyl complexes and the energy of their ${ }^{3}$ MLCT and ${ }^{3} \mathrm{MC}$ states ${ }^{15-21}$ or the topology of their triplet hypersurface. ${ }^{22}$ These studies have demonstrated the critical role of steric hindrance on the ${ }^{3} \mathrm{MLCT}-{ }^{3} \mathrm{MC}$ energy gap, ${ }^{23-28}$ showed that extended conjugation of the bidentate ligand affects the population of ${ }^{3} \mathrm{MC}$ state via competition of low- 
lying bpy-based $\pi-\pi^{*}$ excited state, ${ }^{12,25}$ or explained why thioether ligands are more prone to photosubstitution compared to amines. $^{29}$ Electrochemical studies of $[\mathrm{Ru}(\mathrm{tpy})(\mathrm{N}, \mathrm{N})(\mathrm{L})]^{n+}$ complexes demonstrated that electron-withdrawing bidentate ligands tended to decrease the energy gap between the frontier orbitals (HOMO and LUMO). ${ }^{30}$ However, one question remains poorly addressed, what is the effect of electron-withdrawing spectator ligands that have no additional steric hindrance on the photosubstitution quantum yields?

In this work we aimed at answering this question by studying two series of complexes having the general formula $\left[\mathrm{Ru}(\mathrm{tpy})\left(\mathrm{R}_{2} \mathrm{bpy}\right)(\mathrm{L})\right]^{n+}$ (tpy $=2,2^{\prime}: 6^{\prime}, 2^{\prime \prime}$-terpyridine, $\mathrm{L}=$ monodentate ligand) with two electronically different bidentate ligands: $\mathrm{R}_{2}$ bpy $=4,4^{\prime}$-dimethyl-2,2'-bipyridine (dmbpy) and $\mathrm{R}_{2}$ bpy $=4,4^{\prime}$ bis(trifluoromethyl)-2,2'-bipyridine (tfmbpy). Methyl and trifluoromethyl groups are typical isosteres as the hydrogen and fluorine atoms have comparable sizes. The van der Waals radius of fluorine $(1.35 \AA)$ is the next smallest after hydrogen $(1.20 \AA)$. However, $\mathrm{CH}_{3}$ and $\mathrm{CF}_{3}$ groups have opposite electronic properties because of the large differences in electronegativity and inductive effects of $\mathrm{F} v s . \mathrm{H}:{ }^{31} \mathrm{dmbpy}$ is electrondonating, whereas tfmbpy is electron-withdrawing. Importantly, these substituents were placed in 4 and $4^{\prime}$ position on the bipyridine spectator ligand, so that both series of complexes have rigorously identical steric requirements. The monodentate ligands L were also systematically varied as their electronic properties strongly influence the photosubstitution reaction efficiency: $\mathrm{L}$ was $\mathrm{Cl}^{-}, \mathrm{H}_{2} \mathrm{O}, \mathrm{CH}_{3} \mathrm{CN}, 2$-(methylthio) ethanol (Hmte), or pyridine. The synthesis of ten $[\mathrm{Ru}(\mathrm{tpy})$ $\left(\mathrm{R}_{2}\right.$ bpy $\left.)(\mathrm{L})\right]^{n+}$ complexes is reported, as well as the study of their electrochemical, spectroscopic, and photochemical properties.

\section{Results and discussion}

\section{Ligand synthesis}

Unlike dmbpy, which is commercially available, 4,4'-bis(trifluoromethyl)-bpy was synthesized using a modified method from Liao et al. based on the nickel catalyst $\mathrm{NiCl}_{2} \cdot 6 \mathrm{H}_{2} \mathrm{O}$ (Scheme $\mathrm{S} 1 \dagger$ ). ${ }^{32}$ Our modifications included the change of the solvent from DMF to THF, adding twice as much nickel catalyst as reported, and also one equivalent of 2,2'-bpy per mol catalyst. Iodine and acetic acid were not necessary. As a result, the ligand was obtained with much higher yield (56\%) compared to the original protocol $(10 \%)$. The yield was also improved compared to that reported by Chan et al. where $30 \mathrm{~mol} \%$ of $\mathrm{Ni}\left(\mathrm{PPh}_{3}\right)_{2} \mathrm{Cl}_{2}$, a typical catalyst of Negishi coupling reaction, was used. ${ }^{33}$ The improvement in yield was attributed to two effects. First, the initial formation of $\left[\mathrm{Ni}(\mathrm{bpy}) \mathrm{Cl}_{2}\right]$, which according to Liao et al. facilitates the catalytic cycle, ${ }^{32}$ was verified by ${ }^{1} \mathrm{H}$ NMR spectroscopy: a paramagnetic bpy-containing species $^{34}$ was observed instead of free bpy ligand (Fig. S1 $\dagger$ ). Furthermore, THF being a stronger ligand than DMF, it may stabilize the catalyst by coordinating to nickel throughout the catalytic cycle. $^{35}$ The Experimental section and Fig. S2-S5† show the full characterization of the tfmbpy ligand by ${ }^{1} \mathrm{H},{ }^{13} \mathrm{C}$, ${ }^{19} \mathrm{~F}\left\{{ }^{1} \mathrm{H}\right\}$ NMR spectroscopy, and electrospray mass spectrometry (ES-MS).

\section{Synthesis of $\left[\mathrm{Ru}(\mathrm{tpy})\left(\mathrm{R}_{2} \mathrm{bpy}\right)(\mathrm{L})\right]^{n+}$ complexes}

As illustrated in Scheme 1, the dmbpy and tfmbpy ligands were coordinated to $\left[\mathrm{Ru}(\mathrm{tpy}) \mathrm{Cl}_{3}\right]$ to afford complexes $[\mathbf{1}] \mathrm{Cl}$ and [2]Cl (see Fig. 1 for complex numbers). ${ }^{27,36,37}$ Both complexes had a typical dark violet colour. The ${ }^{1} \mathrm{H}$ NMR spectrum of [2] Cl showed that the protons were de-shielded compared to $[\mathbf{1}] \mathrm{Cl}$. As expected, the chemical shift of the alpha proton of the bipyridine (i.e. B6, see Scheme 1) was noticeably shifted downfield because of the electron-withdrawing trifluoromethyl substituents. ${ }^{38}$ The non-equivalence of the two trifluoromethyl groups was confirmed by two chemical shifts observed in the ${ }^{19} \mathrm{~F}\left\{{ }^{1} \mathrm{H}\right\}$ NMR spectrum, as well as separate B7 and B7' quartets by ${ }^{13} \mathrm{C}$ NMR (see spectra in Fig. S6-S10†).

From the chlorido complexes, the aqua $\left([3]\left(\mathrm{PF}_{6}\right)_{2}\right.$ and $\left.[4]\left(\mathrm{PF}_{6}\right)_{2}\right)$, acetonitrile $\left([5]\left(\mathrm{PF}_{6}\right)_{2}\right.$ and $\left.[6]\left(\mathrm{PF}_{6}\right)_{2}\right)$, thioether $\left([7]\left(\mathrm{PF}_{6}\right)_{2}\right.$ and $\left.[8]\left(\mathrm{PF}_{6}\right)_{2}\right)$, and pyridine $\left([9]\left(\mathrm{PF}_{6}\right)_{2}\right.$ and $\left.[\mathbf{1 0}]\left(\mathrm{PF}_{6}\right)_{2}\right)$ complexes were synthesized using modified literature procedures. ${ }^{25,27,30}$ Generally, the syntheses started from the chlorido complex, which was refluxed under argon with $\mathrm{AgPF}_{6}$ and an excess of the target monodentate ligand (see Experimental section). The difference between the dmbpy and tfmbpy analogues was not very significant except for the syntheses of the aqua complexes. Complex [1] Cl fully converted into $[3]\left(\mathrm{PF}_{6}\right)_{2}$ after refluxing the mixture of $[\mathbf{1}] \mathrm{Cl}$ and $\mathrm{AgPF}_{6}$ in acetone/water for $3 \mathrm{~h}$, whereas [2] Cl showed minimal conversion to $[4]\left(\mathrm{PF}_{6}\right)_{2}$ after $16 \mathrm{~h}$ under the same reaction conditions. Therefore, a microwave reaction was performed, where acetone was excluded to prevent the potential competition with $\mathrm{H}_{2} \mathrm{O}$ for coordination to ruthenium. To remove the starting material,

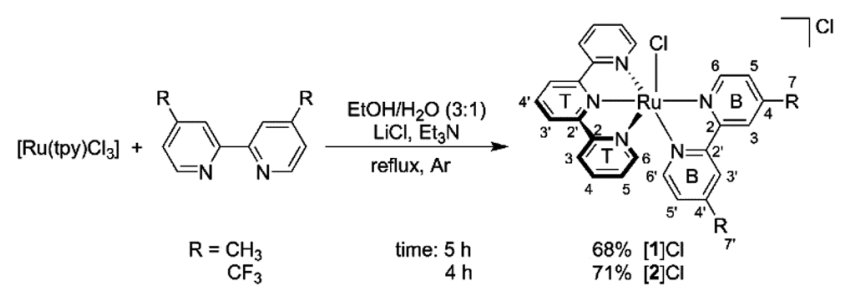

Scheme 1 Synthesis and atom numbering for $\left[R u(t p y)\left(R_{2} b p y\right)(C l)\right] C l$, where $\mathrm{R}_{2}$ bpy $=$ dmbpy $([1] \mathrm{Cl})$ or tfmbpy $([2] \mathrm{Cl})$.

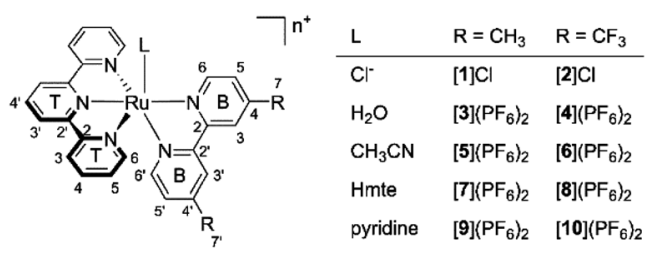

Fig. 1 The synthesized and characterized $\left[R u(t p y)\left(R_{2} b p y\right)(L)\right]^{n+}$ complexes in this work. $n=1$ when $\mathrm{L}=\mathrm{Cl}^{-}$, and $n=2$ when $\mathrm{L}=\mathrm{H}_{2} \mathrm{O}$, $\mathrm{CH}_{3} \mathrm{CN}$, Hmte, or py. 
dichloromethane extraction was used, yielding $[4]\left(\mathrm{PF}_{6}\right)_{2}$ in the aqueous phase (Fig. $\mathrm{S} 13 \dagger$ ).

${ }^{1} \mathrm{H}$ NMR spectroscopy of all the complexes in acetone- $d_{6}$, displayed a trend in the chemical shifts of the alpha proton on the bipyridine ligand (B6). For both the dmbpy and tfmbpy series, the $\mathrm{B} 6$ proton became gradually less de-shielded following the series $\mathrm{Cl}^{-}>\mathrm{Hmte} \approx \mathrm{CH}_{3} \mathrm{CN} \approx \mathrm{H}_{2} \mathrm{O}>$ pyridine (Fig. S20 and $\mathrm{S} 21 \dagger$ ). The particularly upfield-shifted $\mathrm{B} 6$ proton of the pyridine complexes resulted from the shielding cone of the coordinated pyridine ligand, whereas the large downfield shift for the chloride analogues was interpreted as a consequence of the inductive effect of the chloride.

Single crystals of $[1] \mathrm{Cl} \cdot \mathrm{C}_{2} \mathrm{H}_{6} \mathrm{O}, \quad[2]\left(\mathrm{PF}_{6}\right) \cdot \mathrm{C}_{3} \mathrm{H}_{6} \mathrm{O}, \quad[5]$ $\left(\mathrm{PF}_{6}\right)_{2} \cdot 0.70 \mathrm{CH}_{3} \mathrm{CN},[6]\left(\mathrm{PF}_{6}\right)_{2} \cdot \mathrm{CH}_{3} \mathrm{CN},[7]\left(\mathrm{PF}_{6}\right)_{2} \cdot \mathrm{C}_{3} \mathrm{H}_{6} \mathrm{O},[8]\left(\mathrm{PF}_{6}\right)_{2}$, $[\mathbf{9}]\left(\mathrm{PF}_{6}\right)_{2} \cdot \mathrm{C}_{7} \mathrm{H}_{8}$ and $[\mathbf{1 0}]\left(\mathrm{PF}_{6}\right)_{2} \cdot \mathrm{C}_{3} \mathrm{H}_{6} \mathrm{O}$ suitable for X-ray structure determination were obtained by slow vapor diffusion. Specific solvent conditions for crystallization are described in the
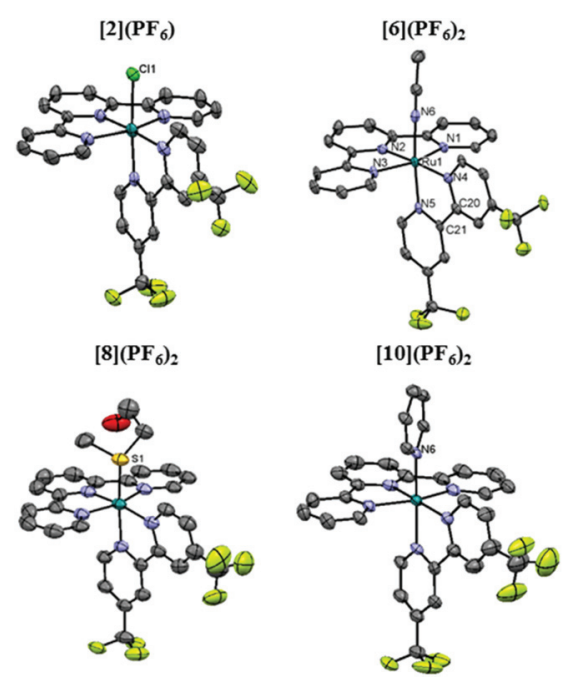

Fig. 2 Displacement ellipsoid plot (50\% probability level) of the crystal structures of $[2]\left(\mathrm{PF}_{6}\right),[6]\left(\mathrm{PF}_{6}\right)_{2},[8]\left(\mathrm{PF}_{6}\right)_{2}$, and $[10]\left(\mathrm{PF}_{6}\right)_{2}$. The counteranions, disorder, hydrogen atoms, and the uncoordinated lattice solvent molecules were omitted for clarity.
Experimental section. The displacement ellipsoid plots of the tfmbpy analogue crystal structures are given in Fig. 2, and the dmbpy analogues are shown in Fig. S34† along with the crystal data in Table S1. $\dagger$ As expected, the complexes display octahedral geometry without significant distortion of the bpy (Fig. 2 and S34† and Table 1). Comparing a dmbpy complex to its tfmbpy analogue (i.e. $[1]^{+}$vs. $[2]^{+}$, or $[5]^{2+}$ vs. $[6]^{2+}$ ), the bond distances from the Ru1 atom to the bidentate ligand were longer for the dmbpy complexes than their tfmbpy analogues. However, the Ru1-L bond distances were not significantly affected by the property of the bidentate ligands, whereas significant variation occurred depending on the heteroatom bound to ruthenium (Table 1 ).

\section{Electrochemical properties}

To gain insight into the frontier orbitals of these complexes, the electrochemical properties of the complexes were studied using cyclic voltammetry (CV). As summarized in Table 2 and

Table 2 Redox potentials and $i_{\mathrm{pa}} / i_{\mathrm{pc}}$ of [1] Cl, [2] $\left(\mathrm{PF}_{6}\right)$, and [5] $\left(\mathrm{PF}_{6}\right)_{2}-[10]$ $\left(\mathrm{PF}_{6}\right)_{2}$ as measured by cyclic voltammetry ${ }^{a}$

\begin{tabular}{|c|c|c|c|c|}
\hline \multirow[b]{2}{*}{ Complex } & \multicolumn{2}{|c|}{$[\text { complex }]^{\{(n+1) / n\}+}$} & \multicolumn{2}{|c|}{$[\text { complex }]^{\{n /(n-1)\}+}$} \\
\hline & $E_{1 / 2}(\mathrm{~V})$ & $i_{\mathrm{pa}} / i_{\mathrm{pc}}$ & $E_{1 / 2}(\mathrm{~V})$ & $i_{\mathrm{pa}} / i_{\mathrm{pc}}$ \\
\hline$[1]^{+}$ & 0.41 & 1.01 & -1.80 & 0.94 \\
\hline$[2]^{+}$ & 0.60 & 1.03 & -1.45 & 0.96 \\
\hline$[5]^{2+}$ & 0.93 & 0.96 & -1.62 & 1.13 \\
\hline$[6]^{2+}$ & 1.12 & 0.86 & -1.33 & 1.07 \\
\hline$[7]^{2+}$ & $0.98^{b}$ & - & -1.57 & 0.60 \\
\hline$[8]^{2+}$ & $1.16^{b}$ & - & -1.33 & 1.09 \\
\hline$[9]^{2+}$ & 0.86 & 0.88 & -1.58 & 1.03 \\
\hline$[10]^{2+}$ & 1.04 & 0.87 & -1.33 & 1.00 \\
\hline$[\mathrm{Ru}(\mathrm{tpy})(\mathrm{bpy})(\mathrm{Cl})]^{+c}$ & 0.42 & & -1.81 & \\
\hline$\left[\mathrm{Ru}(\mathrm{tpy})_{2}\right]^{2+d}$ & 0.92 & & -1.67 & \\
\hline$\left[\mathrm{Ru}(\mathrm{tfmbpy})_{3}\right]^{2+}$ & 0.54 & & -1.22 & \\
\hline$\left[\mathrm{Ru}(\mathrm{dmbpy})_{3}\right]^{2+e}$ & 0.72 & & -1.83 & \\
\hline
\end{tabular}

${ }^{a}$ Measurement conditions: $1 \mathrm{mM}$ of the complexes in $0.1 \mathrm{M} \mathrm{Bu}_{4} \mathrm{NPF}_{6} /$ $\mathrm{CH}_{3} \mathrm{CN}$, scan rate $100 \mathrm{mV} \mathrm{s}^{-1} . n=1$ for $[1]^{+}$and $[2]^{+}$, and $n=2$ for the other complexes. The potentials are referenced to $\mathrm{Fc}^{0 /+} \cdot{ }^{b} E_{\mathrm{pa}} \cdot{ }^{c}$ Ref. 40. ${ }^{d}$ Ref. $41 .{ }^{e}$ Ref. 42 .

Table 1 Selected bond lengths $(\AA)$ and angles $\left(^{\circ}\right)$ in the crystal structures of $[1] \mathrm{Cl}_{2} \cdot \mathrm{C}_{2} \mathrm{H}_{6} \mathrm{O},[2]\left(\mathrm{PF}_{6}\right) \cdot \mathrm{C}_{3} \mathrm{H}_{6} \mathrm{O},[5]\left(\mathrm{PF}_{6}\right)_{2} \cdot 0.70 \mathrm{CH}_{3} \mathrm{CN}_{1}[6]\left(\mathrm{PF}_{6}\right)_{2} \cdot \mathrm{CH}_{3} \mathrm{CN}_{\text {, }}$ $[7]\left(\mathrm{PF}_{6}\right)_{2} \cdot \mathrm{C}_{3} \mathrm{H}_{6} \mathrm{O}$, [8] $\left(\mathrm{PF}_{6}\right)_{2},[9]\left(\mathrm{PF}_{6}\right)_{2} \cdot \mathrm{C}_{7} \mathrm{H}_{8}$ and $[10]\left(\mathrm{PF}_{6}\right)_{2} \cdot \mathrm{C}_{3} \mathrm{H}_{6} \mathrm{O}$

\begin{tabular}{|c|c|c|c|c|c|c|c|c|}
\hline & $\begin{array}{l}{[1]} \\
\mathrm{Cl} \cdot \mathrm{C}_{2} \mathrm{H}_{6} \mathrm{O}\end{array}$ & $\begin{array}{l}{[2]} \\
\left(\mathrm{PF}_{6}\right) \cdot \mathrm{C}_{3} \mathrm{H}_{6} \mathrm{O}\end{array}$ & $\begin{array}{l}{[5]} \\
\left(\mathrm{PF}_{6}\right)_{2} \cdot 0.70 \mathrm{MeCN}^{b}\end{array}$ & $\begin{array}{l}{[6]} \\
\left(\mathrm{PF}_{6}\right)_{2} \cdot \mathrm{CH}_{3} \mathrm{CN}\end{array}$ & $\begin{array}{l}{[7]} \\
\left(\mathrm{PF}_{6}\right)_{2} \cdot \mathrm{C}_{3} \mathrm{H}_{6} \mathrm{O}\end{array}$ & $\begin{array}{l}{[8]} \\
\left(\mathrm{PF}_{6}\right)_{2}\end{array}$ & $\begin{array}{l}{[9]} \\
\left(\mathrm{PF}_{6}\right)_{2} \cdot \mathrm{C}_{7} \mathrm{H}_{8}\end{array}$ & $\begin{array}{l}{[10]} \\
\left(\mathrm{PF}_{6}\right)_{2} \cdot \mathrm{C}_{3} \mathrm{H}_{6} \mathrm{O}\end{array}$ \\
\hline Ru1-N1 & $2.062(4)$ & $2.062(3)$ & $2.076(2)$ & $2.084(5)$ & $2.070(2)$ & $2.078(3)$ & $2.085(2)$ & $2.072(3)$ \\
\hline Ru1-N4 & $2.086(3)$ & $2.070(3)$ & $2.093(6)$ & $2.076(5)$ & $2.099(2)$ & $2.092(4)$ & $2.089(2)$ & $2.077(3)$ \\
\hline Ru1-N5 & $2.047(3)$ & $2.026(3)$ & $2.044(7)$ & $2.033(5)$ & $2.070(2)$ & $2.061(3)$ & $2.056(2)$ & $2.057(3)$ \\
\hline $\mathrm{Ru} 1-\mathrm{L}^{a}$ & $2.3983(9)$ & $2.4050(9)$ & $2.032(2)$ & $2.036(5)$ & $2.3757(7)$ & $2.374(2)$ & $2.100(2)$ & $2.103(3)$ \\
\hline Ru1-N4-C20-C21 & $-6.3(4)$ & $6.9(4)$ & $-4.8(5)$ & $-0.6(6)$ & $2.3(3)$ & $-3.3(5)$ & $2.9(3)$ & $-7(5)$ \\
\hline Ru1-N5-C21-C20 & $3.7(5)$ & $-4.8(4)$ & $4.5(5)$ & $0.8(6)$ & $-1.1(3)$ & $-2.0(5)$ & $1.8(3)$ & $-7(3)$ \\
\hline
\end{tabular}

${ }^{a} \mathrm{~L}=\mathrm{Cl} 1$ for $[1] \mathrm{Cl}$ and $[2]\left(\mathrm{PF}_{6}\right)$; N6 for $[5]\left(\mathrm{PF}_{6}\right)_{2},[6]\left(\mathrm{PF}_{6}\right)_{2},[9]\left(\mathrm{PF}_{6}\right)_{2}$, and $[10]\left(\mathrm{PF}_{6}\right)_{2}$; or $\mathrm{S} 1$ for $[7]\left(\mathrm{PF}_{6}\right)_{2}$ and $[8]\left(\mathrm{PF}_{6}\right)_{2}$. See Fig. S34. ${ }^{b} \mathrm{~A}$ crystal structure of $[5]\left(\mathrm{PF}_{6}\right)_{2}$ was previously reported ${ }^{39}$ with comparable parameters as the data in this table. 


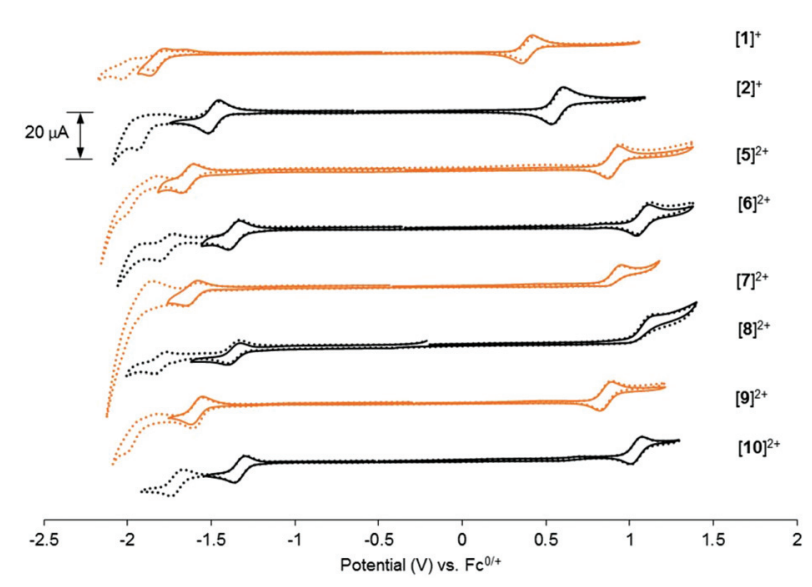

Fig. 3 Cyclic voltammograms of $1 \mathrm{mM}$ [1]Cl, [2] $\left(\mathrm{PF}_{6}\right)$, or $[5]\left(\mathrm{PF}_{6}\right)_{2}$ through $[10]\left(\mathrm{PF}_{6}\right)_{2}$ in $0.1 \mathrm{M} \mathrm{Bu}_{4} \mathrm{NPF}_{6} / \mathrm{CH}_{3} \mathrm{CN}\left(\nu=100 \mathrm{mV} \mathrm{s}{ }^{-1}\right)$. The orange lines represent the $4,4^{\prime}$-dimethyl-2,2'-bipyridine analogues and the black lines represent the 4,4'-bis(trifluoromethyl)-2,2'-bipyridine analogues. Dashed lines show the second ligand-based reductions of the complexes.

Fig. 3, the dmbpy and tfmbpy complexes showed clear differences in oxidation and reduction potentials. Irrespective of the monodentate ligand, the half-wave potential of the Ru-based oxidation for the tfmbpy complex was 100-200 mV higher than that of the dmbpy complex. The shift to higher potential for the tfmbpy analogues was expected as the electron-withdrawing substituents decreased the electron density of the metal center, making the $\mathrm{Ru}^{\mathrm{II}}$ to $\mathrm{Ru}^{\mathrm{III}}$ oxidation more difficult. Similarly, the half-wave potential of the ligand-based reduction for the tfmbpy complex was more negative than that of the dmbpy complexes. This result is consistent with the trifluoromethyl groups stabilizing the extra charge added on the reduced ligand, which makes reduction more favourable. In Fig. 4, an energy diagram derived from Table 2 clearly shows that the stabilization of the LUMO from the dmbpy to the tfmbpy complexes was greater than that of the HOMO. For ruthenium polypyridyl complexes, the LUMO is usually more ligand-based than the HOMO. Here, comparison of the LUMOs for $[\mathrm{Ru}(\mathrm{tpy})(\mathrm{bpy})(\mathrm{Cl})]^{+}\left(-1.81 \mathrm{~V} v\right.$ s. $\left.\mathrm{Fc}^{\mathrm{0} /+}\right),{ }^{40}\left[\mathrm{Ru}(\mathrm{tpy})_{2}\right]^{2+}$ $\left(-1.67 \mathrm{~V}\right.$ vs. $\left.\mathrm{Fc}^{0 /+}\right),{ }^{41}$ and $\left[\mathrm{Ru}(\mathrm{tfmbpy})_{3}\right]^{2+}\left(-1.22 \mathrm{~V}\right.$ vs. $\left.\mathrm{Fc}^{0 /+}\right)$ (Fig. S35†) suggested that the LUMO of the dmbpy complexes was tpy-based, whereas that of the tfmbpy complexes was mostly localized on the tfmbpy ligand.

In addition to the energy of the frontier orbitals, the electronic effects also influenced the lability of the monodentate ligand. As previously reported, the cyclic voltammogram of $[\mathbf{1}]^{+}$ showed that the $\mathrm{Cl}^{-}$ligand was replaced by $\mathrm{CH}_{3} \mathrm{CN}$ after the first ligand-based reduction. ${ }^{30}$ This was indicated by oxidation occurring at about $-1.65 \mathrm{~V}$ during anodic scanning. In contrast, the ligand substitution was not observed in the CV scan of $[2]^{+}$. The inertness of the complex was previously attributed to the localization of the extra charge in electron-deficient tfmbpy rather than in the $\mathrm{Ru}-\mathrm{Cl}$ bond. Unfortunately, it was difficult to discern whether such differences in ligand lability

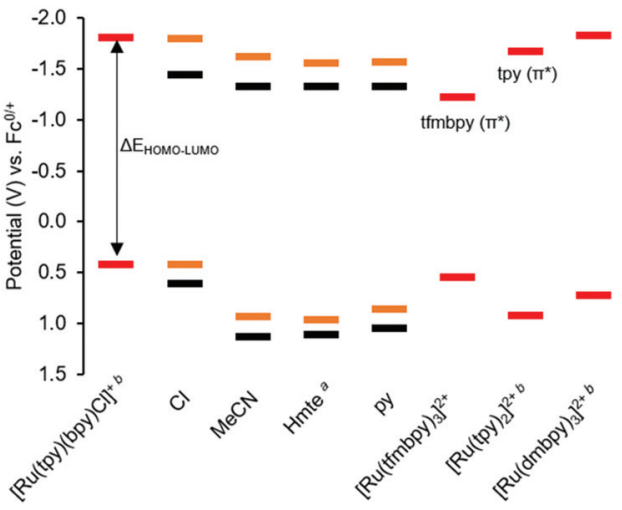

Fig. 4 HOMO and LUMO orbital energy diagram derived from cyclic voltammetry data (Table 2). The orange lines represent the 4,4'dimethyl-2,2'-bipyridine analogues $[1]^{+},[5]^{2+},[7]^{2+},[9]^{2+}$, and the black lines represent the $4,4^{\prime}$-bis(trifluoromethyl)-2,2'-bipyridine analogues $[2]^{+},[6]^{2+},[8]^{2+},[10]^{2+}$, with the monodentate ligands specified on the $x$-axis. The red lines represent the $E_{1 / 2}$ of the first metal-based oxidation and ligand-based reduction of the references. ${ }^{a}$ For both Hmte complexes, $E_{1 / 2}$ was calculated from the electrochemical data measured with a scan rate of $1000 \mathrm{mV} \mathrm{s}^{-1}$, and used in this chart, instead of the $E_{\mathrm{pa}}$ in Table 2. ${ }^{b}$ The potentials were previously reported. ${ }^{40-42}$

between the dmbpy and tfmbpy complexes was present for the other monodentate ligands due to the significant overlap of the $E_{\mathrm{pa}}$ of the first ligand-based reduction.

In addition to the electronic effects observed for the dmbpy and tfmbpy analogues on the LUMO, the monodentate ligands influenced the $\mathrm{Ru}^{\mathrm{III}} / \mathrm{Ru}^{\mathrm{II}}$ oxidation potentials, hence the HOMO energy level in these complexes. The HOMO of the chloride complexes appeared at lower potentials $(\sim 0.5 \mathrm{~V} v s$. $\mathrm{Fc}^{0 /+}$ ) due to the $\pi$-donor character of the $\mathrm{Cl}^{-}$ligand, while the difference among the $\mathrm{CH}_{3} \mathrm{CN}$, Hmte, and pyridine complexes was found negligible. The stabilization of the HOMO, for example, from $[\mathbf{1}]^{+}$to $[5]^{2+}$ was greater than the stabilization of the HOMO from $[1]^{+}$to $[2]^{+}$, meaning that the monodentate ligands affected the HOMO more than the LUMO. Also of interest are the metal-based oxidations for the Hmte complexes $[7]^{2+}$ and $[8]^{2+}$, which were the only ones to show irreversible character. Such deviation was ascribed to the character of the sulphur atom whose affinity for $\mathrm{Ru}^{\mathrm{III}}$ is weaker than for $\mathrm{Ru}^{\mathrm{II}}$. Hence, the $\mathrm{Ru}-\mathrm{S}$ bond was likely to dissociate upon oxidation of the metal center, and thus the $E_{\mathrm{pc}}$ of the original sulphur-binding complex was not observed. Though it is possible that the oxygen atom on Hmte, which is a hard base compared to sulphur, binds to $\mathrm{Ru}$, the question whether the $\mathrm{S}-\mathrm{O}$ linkage isomerization occurred like in the ruthenium-sulfoxide complexes, is unclear from these results. ${ }^{43}$ When the scan rate was increased to $2000 \mathrm{mV} \mathrm{s}^{-1}$, the cathodic peak for the reduction of $\mathrm{Ru}^{\mathrm{III}}$ could be detected, i.e. the electrochemical $\mathrm{Ru}^{\mathrm{III}} / \mathrm{Ru}^{\mathrm{II}}$ couple became more reversible (Fig. S36 and S37 $\dagger$ ). In this respect, the irreversibility at standard scan rates seems to be an indication of the increased lability of the Hmte ligand when the metal center becomes electron-deficient. This result will be revisited in relation to the photosubstitution results. 


\section{Electronic absorption properties}

In order to investigate how the changes in the frontier orbital energy levels are reflected in the ${ }^{1}$ MLCT transitions, the electronic absorption spectra of the Ru complexes were measured in acetonitrile (except for the aqua complexes, which were measured in acetone). Each of the spectra revealed intense MLCT-based transitions between 450-530 nm, summarized in Table 3 and Fig. 5 (see Fig. S38† for the spectra of the aqua complexes). Overall, the wavelength of the ${ }^{1}$ MLCT transition $\left(\lambda_{\text {max }}^{\text {abs }}\right)$ for the tfmbpy complexes occurred at lower energy than the dmbpy analogues. Thus, the tfmbpy ligand decreased the HOMO-LUMO gap, compared to dmbpy. The spectra of the dmbpy complexes were analogous to those of the $[\mathrm{Ru}(\mathrm{tpy})(\mathrm{bpy})$ $(\mathrm{L})]^{n+}$ complexes in that the weak absorptions (band I and II) were observed at lower energy than the dominant ${ }^{1}$ MLCT transition. ${ }^{40}$ The bands were not as resolved for the tfmbpy complexes. When the energy of the dominant ${ }^{1}$ MLCT transitions, which was calculated from the $\lambda_{\max }^{\text {abs }}$, was plotted against $\Delta E_{\text {HOMO-LUMO }}$, the potential difference between the $E_{1 / 2}$ of the HOMO and LUMO (Fig. 6), the eight complexes generally fit a linear trend $\left(R^{2}=0.9845\right)$. Nevertheless, the $R^{2}$ slightly improved (0.9937 and 0.9898) when two separate trends were obtained for the respective series of complexes. This divergence between the dmbpy and tfmbpy series presumably results from the different nature of the ${ }^{1} \mathrm{MLCT}$ transition, likely due to the change in the character of the LUMO.

\section{Photochemistry}

The impact of the bidentate and monodentate ligands on light-induced ligand substitution was studied in acetonitrile as illustrated in Scheme 2. The $\mathrm{Cl}^{-}$, pyridine, or Hmte analogues were irradiated in $\mathrm{CH}_{3} \mathrm{CN}$ by $490 \mathrm{~nm}$ light for 30 minutes at $25{ }^{\circ} \mathrm{C}$. The reactions were monitored by electronic absorption spectroscopy, and the end product was analysed using ${ }^{1} \mathrm{H}$ NMR spectroscopy and electrospray mass spectrometry (ES-MS).

The monodentate photosubstitution rate was considerably affected by the choice of coordinated monodentate ligand rather than by that of the bidentate ligand. The most unreactive analogue among the three was the chlorido complexes $[\mathbf{1}]^{+}$ and $[2]^{+}$: no photoconversion was observed according to electronic absorption spectra (Fig. S39 and S40†). ES-MS at the
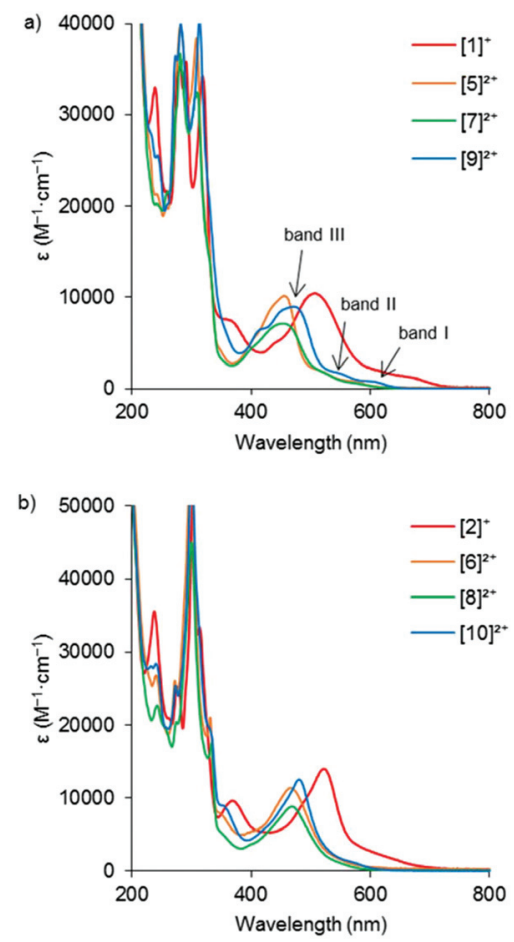

Fig. 5 Electronic absorption spectra of (a) $[R u(t p y)(d m b p y)(L)]^{n+}$, and (b) $[R u(t p y)(t f m b p y)(L)]^{n+}$. Three of the ${ }^{1} M L C T$ transitions were labelled in the spectrum of $[9]^{2+}$ as an example.

end of the irradiation only showed the starting complex (Fig. S41 and S42†). The inertness of the $\mathrm{Cl}^{-}$ligand is attributed to the strong $\pi$-donor character of the ligand, in addition to a particularly low energy ${ }^{1} \mathrm{MLCT}$, which theoretically extends the energy gap between the ${ }^{3} \mathrm{MLCT}$ and ${ }^{3} \mathrm{MC}$ states, and thus lowers photosubstitution rates. In the case of the photoreactions of $[\mathbf{9}]^{2+}$ and $[\mathbf{1 0}]^{2+}$, a slow shift of the $\lambda_{\max }^{\text {abs }}$ towards higher energy wavelengths was observed upon visible light irradiation, and isosbestic points were observed at $465 \mathrm{~nm}$ and $467 \mathrm{~nm}$ on each of the electronic absorption spectra (Fig. S43 and S44†). ES-MS confirmed that the shift resulted from the replacement of the pyridyl ligand by $\mathrm{CH}_{3} \mathrm{CN}$, resulting in complexes $[5]^{2+}$ and $[6]^{2+}$, respectively (Fig. S45 and S46†). Due to the low conversion of the photoreaction, the photoproducts were difficult to discern by ${ }^{1} \mathrm{H}$ NMR spectroscopy (Fig. S47 and S48†).

Table 3 Wavelength of ${ }^{1} \mathrm{MLCT}$ transition $\left(\lambda_{\max }^{\text {abs }}\right)$, molar absorptivity $\left(\varepsilon\left(\mathrm{M}^{-1} \mathrm{~cm}^{-1}\right)\right)$, and quantum yields of ligand photosubstitution $\left(\Phi_{\mathrm{PS}}\right)$ of $[R u(t p y)$ $\left.\left(\mathrm{R}_{2} \mathrm{bpy}\right)(\mathrm{L})\right]\left(\mathrm{PF}_{6}\right)_{n}$ complexes $^{\mathrm{a}}$

\begin{tabular}{|c|c|c|c|c|c|c|}
\hline \multirow[b]{2}{*}{$\mathrm{L}$} & \multicolumn{3}{|c|}{$[\mathrm{Ru}(\mathrm{tpy})(\mathrm{dmbpy})(\mathrm{L})]\left(\mathrm{PF}_{6}\right)_{n}$} & \multicolumn{3}{|c|}{$[\mathrm{Ru}(\mathrm{tpy})(\mathrm{tfmbpy})(\mathrm{L})]\left(\mathrm{PF}_{6}\right)_{n}$} \\
\hline & $\lambda_{\max }^{\mathrm{abs}}(\mathrm{nm})$ & $\varepsilon\left(\mathrm{M}^{-1} \mathrm{~cm}^{-1}\right)$ & $\Phi_{\mathrm{PS}}$ & $\lambda_{\max }^{\mathrm{abs}}(\mathrm{nm})$ & $\varepsilon\left(\mathrm{M}^{-1} \mathrm{~cm}^{-1}\right)$ & $\Phi_{\mathrm{PS}}$ \\
\hline $\mathrm{Cl}^{-}$ & 506 & 10500 & - & 522 & 14100 & - \\
\hline $\mathrm{MeCN}$ & 456 & 10100 & - & 467 & 10900 & - \\
\hline Hmte & 455 & 7000 & 0.011 & 468 & 8700 & 0.038 \\
\hline Py & 470 & 9100 & $5.1 \times 10^{-5}$ & 481 & 12400 & $6.5 \times 10^{-5}$ \\
\hline $\mathrm{H}_{2} \mathrm{O}^{b}$ & 488 & 9600 & - & 494 & 6700 & - \\
\hline
\end{tabular}

${ }^{a}$ Measured in $\mathrm{CH}_{3} \mathrm{CN}$ at $25^{\circ} \mathrm{C}$ unless otherwise specified. ${ }^{b}$ Measured in acetone. 


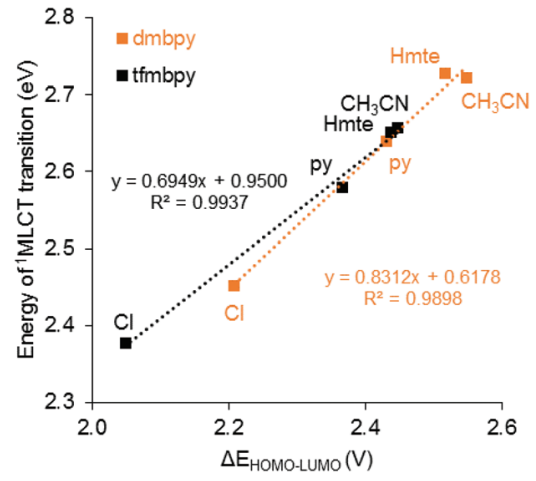

Fig. 6 Plot of the ${ }^{1}$ MLCT transition energy calculated from $\lambda_{\max }^{\text {abs }}$ versus the difference between the Ru-based oxidation potential and the first ligand-based reduction potential ( $\Delta E_{\text {HOMO-LUMO }}$ ) obtained from cyclic voltammetry. The orange lines represent the 4,4'-dimethyl-2,2'-bipyridine analogues and the black lines represent the 4,4'-bis(trifluoromethyl)-2,2'-bipyridine analogues.

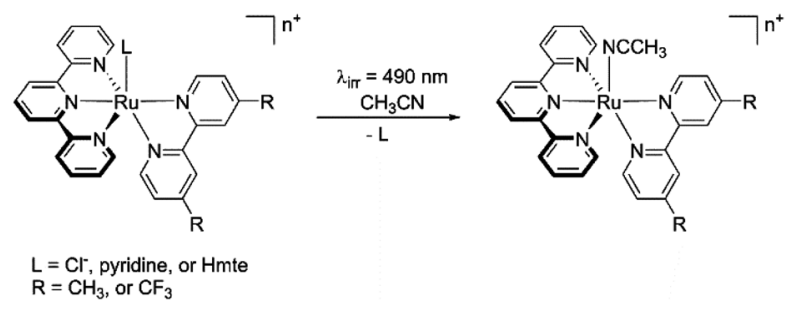

Scheme 2 Scheme of visible light-induced ligand exchange reaction.

However, the reaction kinetics showed first-order behaviour, and the rate constant $\left(k_{\Phi_{\mathrm{PS}}}\right)$ of the tfmbpy complex was approximately twice larger than that of the dmbpy analogue. The quantum yields of ligand photosubstitution $\left(\Phi_{\mathrm{PS}}\right)$ were estimated using eqn (1), ${ }^{27}$

$$
k_{\phi_{\mathrm{PS}}}=\frac{\phi \cdot \phi_{\mathrm{PS}} \times\left(1-10^{-A_{\mathrm{e}}}\right)}{n_{\mathrm{Ru}(\mathrm{tot})}}
$$

where $\Phi$ is photon flux $\left(\mathrm{mol} \mathrm{s}{ }^{-1}\right), A_{\mathrm{e}}$ is absorbance at the irradiation wavelength, and $n_{\mathrm{Ru}(\mathrm{tot})}$ is the total number of moles of Ru complexes (mol) (Table S2 $\dagger$ ). For complexes $[9]^{2+}$ and $[\mathbf{1 0}]^{2+} \Phi_{\mathrm{PS}}$ was found lower than $10^{-4}$ for both complexes (Table 3).

Unlike the chloride and pyridine analogues, the Hmte ligand in complexes $[7]^{2+}$ and $[8]^{2+}$ were readily substituted by $\mathrm{CH}_{3} \mathrm{CN}$ upon visible light irradiation. As shown in Fig. 7 and $\mathrm{S} 50, \uparrow$ the selectivity of the photoreaction was indicated by clear isosbestic points in the electronic absorption spectra at $475 \mathrm{~nm}$ for $[7]^{2+}$, and 497 and $266 \mathrm{~nm}$ for $[8]^{2+}$, despite negligible shift of the absorption maxima $\lambda_{\text {max }}^{\text {abs }}$. Within $10 \mathrm{~min}$, the spectra of $[8]^{2+}$ became time-independent, suggesting quick conversion to the $\mathrm{CH}_{3} \mathrm{CN}$ complex (Fig. S49b广). In addition, ES-MS and ${ }^{1} \mathrm{H}$ NMR spectra at the final time point supported the displacement of the Hmte ligand and the full consumption

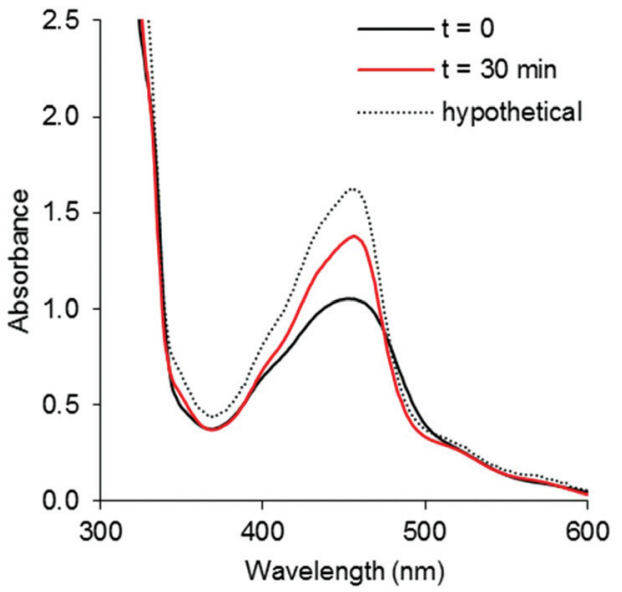

Fig. 7 UV-vis spectra of (a) [7] $\left(\mathrm{PF}_{6}\right)_{2}$ irradiated by $490 \mathrm{~nm}$ light (photon flux $=1.08 \times 10^{-7} \mathrm{~mol} \mathrm{~s}^{-1}$ ) in $\mathrm{CH}_{3} \mathrm{CN}$ for $30 \mathrm{~min},[\mathrm{Ru}]_{\text {tot }}=1.6 \times 10^{-4}$ $M$. Dashed line shows the spectrum expected for full conversion into $[5]^{2+}$, black line shows the initial spectrum, and red line shows the spectrum obtained after 30 min irradiation.

of the starting complexes (Fig. S52-S55†). The tfmbpy complex was noticeably more reactive than the dmbpy analogue (Fig. S51†), with $\Phi_{\mathrm{PS}}$ of 0.038 for $[8]^{2+}$ vs. 0.011 for $[7]^{2+}$ (Table 3). These results demonstrate that the electron-withdrawing tfmbpy ligand considerably improved the efficiency of the photosubstitution reaction. Such increased reactivity was not observed in the ground states, as in complexes $[7]^{2+}-[\mathbf{1 0}]^{2+}$ were all stable at room temperature over $12 \mathrm{~h}$ in the dark (Fig. S56-S59†).

In ruthenium polypyridyl complexes thermal population of the ${ }^{3} \mathrm{MC}$ state from the photochemically generated ${ }^{3} \mathrm{MLCT}$ based excited state is usually claimed to determine whether photosubstitution or ${ }^{3}$ MLCT-based phosphorescence will occur. Both processes compete with each other, so that a higher emission quantum yield is usually associated with a lower photosubstitution efficiency. Looking at the particular case of the thioether monodentate ligand (Hmte), the electronwithdrawing properties of tfmbpy are expected to lower the ligand field splitting parameter of $[8]^{2+}$ and thus the energy level of its ${ }^{3} \mathrm{MC}$ state, compared to $[7]^{2+}$. If the ${ }^{3} \mathrm{MLCT}$ remains at the same energy, complex $[8]^{2+}$ would have a smaller ${ }^{3} \mathrm{MC}-{ }^{3} \mathrm{MLCT}$ gap and therefore a higher photosubstitution quantum yield, which was supported by the $\Phi_{\mathrm{PS}}$ for $[8]^{2+}$ being four times higher than for $[7]^{2+}$. This interpretation also suggests that the phosphorescence of $[8]^{2+}$ should be weaker than that of $[7]^{2+}$. The ${ }^{3}$ MLCT-based phosphorescence for this family of complexes is typically very weak, with emission quantum yields $\left(\Phi_{\mathrm{em}}\right)$ in the range of $10^{-4}$ to $10^{-5}$, but it can be measured (Table S3 $\dagger$ ). Unexpectedly, we found that $[8]^{2+}$ displayed a slightly more intense $\left(\Phi_{\mathrm{em}}=1.1 \times 10^{-4}\right)$ and redshifted emission $(699 \mathrm{~nm})$ compared to $[7]^{2+}\left(640 \mathrm{~nm}, \Phi_{\mathrm{em}}=\right.$ $3.5 \times 10^{-5}$ ). These facts are consistent with the electrochemical results suggesting that the LUMO is terpyridine-based for $[7]^{2+}$, but tfmbpy-based for $[8]^{2+}$. Due to the electron-withdrawing 
effect of the trifluoromethyl groups, putting an electron in the $\operatorname{tfmbpy}\left(\pi^{*}\right)$-based orbital must contribute to stabilizing the ${ }^{3}$ MLCT state of $[\mathbf{8}]^{2+}$, which should red shift the emission maximum for this complex and lower the photosubstitution quantum yield. In other words, $[8]^{2+}$ has both a lower ${ }^{3}$ MLCT state and a lower ${ }^{3} \mathrm{MC}$ state compared to $[7]^{2+}$, which makes any comparison of the relative values of phosphorescence and photosubstitution quantum yields difficult.

On the other hand, in the ${ }^{3}$ MLCT state of $[8]^{2+}$ the electron promoted in the $\pi^{*}(\mathrm{tfmbpy})$ orbital lies first in a plane that contains the $\mathrm{Ru}-\mathrm{S}$ bond (Fig. 8b), and second trans to the
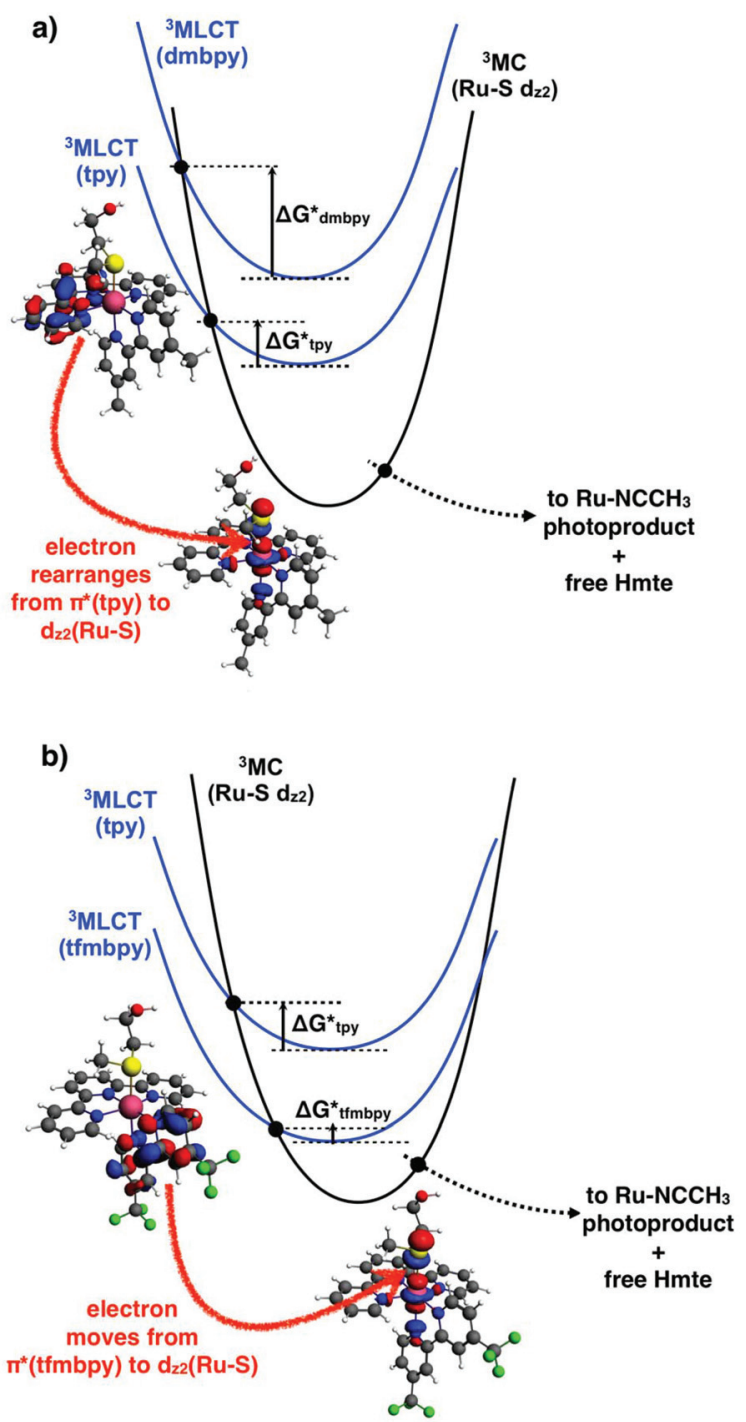

Fig. 8 Triplet potential energy curves showing interconversion of a terpyridine- or bipyridine-based ${ }^{3}$ MLCT state (blue) in (a) $[7]^{2+}$ or (b) $[8]^{2+}$, respectively, into the ${ }^{3} \mathrm{MC}$ state (black) leading to $\mathrm{Ru}-\mathrm{S}$ bond breakage. The HOMOs of the ${ }^{3} \mathrm{MLCT}$ and ${ }^{3} \mathrm{MC}$ states are also calculated at the PBE0/TZP/COSMO level and shown for $[7]^{2+}$ and $[8]^{2+}$. Black dots represent transition states on the triplet hypersurface. $Y$-Axis (potential energy), ground states, ${ }^{1}$ MLCT states, and photoproducts, are not shown for clarity.
Hmte ligand, which presumably elongates the Ru-S bond due to polarization effects. ${ }^{44}$ Both factors may contribute to enhancing the rate of the ${ }^{3} \mathrm{MLCT} \rightarrow{ }^{3} \mathrm{MC}$ transition, and indeed the photosubstitution quantum yield for this complex is higher than that of $[7]^{2+}$ (in the same solvent). In the ${ }^{3}$ MLCT state of $[7]^{2+}$ an electron is promoted to the tpy $\left(\pi^{*}\right)$-based orbital that lies in a plane perpendicular to the $\mathrm{Ru}-\mathrm{S}$ bond (Fig. 8a), which may lower the coupling with the ${ }^{3} \mathrm{MC}$ excited state, and hence the rate of the ${ }^{3} \mathrm{MLCT} \rightarrow{ }^{3} \mathrm{MC}$ transition. The fact that for $[7]^{2+}$ both the emission and the photosubstitution quantum yields are lower than for $[8]^{2+}$ also suggests that non-radiative decay processes that do not go via the ${ }^{3} \mathrm{MC}$ states may also play a role in the deactivation mechanism of the ${ }^{3}$ MLCT state of these ruthenium complexes. Overall, the electronic effects of the tfmbpy ligand seem not only to change the relative energy levels of the ${ }^{3}$ MLCT and ${ }^{3} \mathrm{MC}$ states (Fig. 8), but they also change the geography and the geometry of the electronic density distribution in the ${ }^{3}$ MLCT excited states, and thus the electronic rearrangements necessary to perform the ${ }^{3}$ MLCT $\rightarrow$ ${ }^{3} \mathrm{MC}$ transition.

In the discussion on the irreversibility of the $\mathrm{Ru}$ oxidation for the $\left[\mathrm{Ru}(\mathrm{tpy})\left(\mathrm{R}_{2} \mathrm{bpy}\right)(\mathrm{Hmte})\right]^{2+}$ complexes, we mentioned that the degree of reversibility of the oxidation peak was a measure of ligand lability in the ground state. It seems that it is also correlated to the variation of ligand lability in the excited state. Indeed, we observe that reversible metal-based oxidation is synonymous with photochemical inertness of the monodentate ligand. For instance, the metal-based redox reaction of the chlorido complexes $[1]^{+}$and $[2]^{+}$was highly reversible $\left(i_{\mathrm{pc}} / i_{\mathrm{pa}} \approx 1.0\right)$, and they were found extremely unreactive upon light irradiation. In contrast, the $E_{\mathrm{pc}}$ of the Hmte analogues $[7]^{2+}$ and $[8]^{2+}$ were not observed, i.e. the oxidation peaks were highly irreversible, but they displayed increased photosubstitution of Hmte, compared to the chloride complexes. The pyridine complexes displayed quasi-reversible behaviour and very slow photoconversion. This correlation is reasonable as the electrochemical oxidation and the photochemical transition to ${ }^{3}$ MLCT states share great similarities, as in the ${ }^{3}$ MLCT state an electron is excited from the metal-based HOMO to a ligand-based LUMO orbital, thereby formally increasing the oxidation state of the metal in the excited state to $\mathrm{Ru}^{\mathrm{III}}$. In this respect, reversibility of the Ru-based oxidation as measured by $\mathrm{CV}$ is a useful way to predict the lability of the monodentate ligand upon light irradiation. This correlation mostly depends on the monodentate ligand and not to be strongly affected by the electronic property of the bipyridine ligand.

\section{Conclusion}

This work represents one of the few examples of a series of ruthenium polypyridyl complexes investigating solely the effect of the electronic properties of the bidentate spectator ligand on photosubstitution reactions. Focusing on complexes of the type $\left[\mathrm{Ru}(\mathrm{tpy})\left(\mathrm{R}_{2} \mathrm{bpy}\right)(\mathrm{L})\right]^{n+}$, our work clearly demonstrates that 
the monodentate ligand $(\mathrm{L})$ more strongly affected the $\mathrm{Ru}(\mathrm{d} \pi)$ based HOMO orbitals than the ligand $\left(\pi^{*}\right)$-based LUMO: the more $\pi$-donating $\mathrm{Cl}$ analogue displayed $0.5 \mathrm{~V}$ more positive $\mathrm{Ru}^{\mathrm{III}} / \mathrm{Ru}^{\mathrm{II}}$ redox couple compared to the more $\pi$-accepting ligands $\mathrm{CH}_{3} \mathrm{CN}$, or pyridine. By contrast, the electron-withdrawing tfmbpy ligand stabilized both the HOMO and LUMO, which changed the electronic distribution in the ${ }^{3}$ MLCT state, compared to complexes based on dmbpy. The dmbpy complexes displayed typical $\mathrm{Ru}(\mathrm{d} \pi) \rightarrow \operatorname{tpy}\left(\pi^{*}\right)$-based MLCT states, while the tfmbpy analogues displayed $\operatorname{Ru}(\mathrm{d} \pi) \rightarrow \operatorname{tfmbpy}\left(\pi^{*}\right)-$ based MLCT states. Such changes have counter-intuitive effects on the photochemical properties of the tfmbpy complexes. On the one hand, the ${ }^{1}$ MLCT absorption band is redshifted by $8-16 \mathrm{~nm}$ and the weak ${ }^{3}$ MLCT phosphorescence is red-shifted by $52-59 \mathrm{~nm}$. On the other hand, for the Hmte and pyridine adducts, which were the only ones to be photosubstitutionally reactive in acetonitrile, the tfmbpy complexes displayed up to a 4 times higher photosubstitution quantum yield, compared to the dmbpy analogue, although both the ${ }^{3} \mathrm{MLCT}$ and ${ }^{3} \mathrm{MC}$ states are predicted to be stabilized by the electron-withdrawing group. These results open interesting questions, such as whether it is possible to play on the electron donating and accepting properties of the spectator ligands to design ruthenium complexes that can photosubstitute ligands at higher quantum efficiencies using lower energy light.

\section{Experimental section}

\section{General specifications}

All reagents for which the synthesis is not given were commercially available from Sigma-Aldrich, J. T. Baker, Alfa Aesar, or Actu-All Chemicals, and they were used as received from the suppliers. The ruthenium precursor $\left[\mathrm{Ru}(\mathrm{tpy}) \mathrm{Cl}_{3}\right]$ was prepared following literature method. ${ }^{45}$ Microwave reaction was performed using a Biotage Initiator. ${ }^{1} \mathrm{H},{ }^{13} \mathrm{C}$, and ${ }^{19} \mathrm{~F}\left\{{ }^{1} \mathrm{H}\right\}$ NMR spectra were recorded on a Bruker DPX-300, AV-400, AV-500, or AV-600 spectrometer, all at room temperature. Electronic absorption spectroscopy was recorded using a Varian Cary 50 UV-vis spectrometer. Electrospray mass spectra were obtained by Dionex UltiMate 3000 HPLC.

4,4'-Bis(trifluoromethyl)-2,2'-bipyridine. Nickel(II) chloride hexahydrate (71 $\mathrm{mg}, 0.30 \mathrm{mmol}$ ) was added to dry THF $(50 \mathrm{~mL})$ and the solution was heated to $40{ }^{\circ} \mathrm{C}$ to dissolve the solid. To the pale yellow solution, 2,2'-bpy (47 mg, $0.30 \mathrm{mmol}$ ) was added, which turned green. Then 2-bromo-4-trifluoromethylpyridine (679 mg, $3.0 \mathrm{mmol}$ ), Zn (245 mg, $3.75 \mathrm{mmol}$ ), and $\mathrm{LiCl}(127 \mathrm{mg}, 3.0 \mathrm{mmol}$ ) were added, and the reaction was heated at $60{ }^{\circ} \mathrm{C}$ for $5 \mathrm{~h}$ under Ar. When the reaction was complete as monitored by TLC (silica gel, hexane/DCM $(6: 1)$ ), $\sim 5 \mathrm{~mL}$ of $1 \mathrm{M} \mathrm{HCl}$ was added to consume the remaining $\mathrm{Zn}$, followed by the addition of ammonium hydroxide $\left(25 \% \mathrm{NH}_{3}\right)$ until the mixture became alkaline. THF was rotary evaporated, and DCM and water were added for extraction $(\sim 70 \mathrm{~mL} \times 3)$. The organic phase was washed with water, extracted again, and dried with $\mathrm{MgSO}_{4}$. After filtration, the solvent was removed. The crude product was purified by silica gel column chromatography using hexane/DCM $(6: 1)\left(R_{\mathrm{f}}=0.28\right)$. The solvent was evaporated to yield a white solid (247 mg, 56\%). ${ }^{1} \mathrm{H}$ NMR (400 $\mathrm{MHz}, \mathrm{CDCl}_{3}$ ) agreed with literature. ${ }^{46}{ }^{1} \mathrm{H}$ NMR (500 MHz, CD $\mathrm{CD}_{3} \mathrm{OD} \delta 8.95(\mathrm{~d}, J=5.0 \mathrm{~Hz}, 1 \mathrm{H}, \mathrm{H} 6), 8.73(\mathrm{~s}, 1 \mathrm{H}$, H3), $7.77 \mathrm{ppm}(\mathrm{dd}, J=5.1,1.1 \mathrm{~Hz}, 1 \mathrm{H}, \mathrm{H} 5) .{ }^{13} \mathrm{C} \mathrm{NMR}$ (500 MHz, CD $\left.{ }_{3} \mathrm{OD}\right): \delta 157.3$ (s, C2), 152.1 (s, C6), $140.6\left(\mathrm{q},{ }^{2} J_{\mathrm{CF}}\right.$ $=34.0 \mathrm{~Hz}, \mathrm{C} 4), 124.4\left(\mathrm{q},{ }^{1} J_{\mathrm{CF}}=272.3 \mathrm{~Hz}, \mathrm{C} 7\right), 121.3\left(\mathrm{q},{ }^{3} J_{\mathrm{CF}}=\right.$ $3.5 \mathrm{~Hz}, \mathrm{C} 5), 117.7 \mathrm{ppm}\left(\mathrm{q},{ }^{3} J_{\mathrm{CF}}=3.8 \mathrm{~Hz}, \mathrm{C} 3\right) .{ }^{19} \mathrm{~F}\left\{{ }^{1} \mathrm{H}\right\} \mathrm{NMR}$ (500 MHz, $\left.\mathrm{CD}_{3} \mathrm{OD}\right): \delta-66.5$ ppm. MS: $m / z$ 293.0, $[\mathrm{L}+\mathrm{H}]^{+}$ (calc.: 293.1).

$\left[\mathbf{R u}(\right.$ tpy)(dmbpy)Cl $] \mathbf{C l} \quad([1] \mathrm{Cl}) . \quad\left[\mathrm{Ru}\left(\mathrm{tpy}_{\mathrm{C}} \mathrm{Cl}_{3}\right] \quad(500 \quad \mathrm{mg}\right.$, $1.1 \mathrm{mmol}$ ), 4,4'-dmbpy (210 mg, $1.1 \mathrm{mmol}), \mathrm{Et}_{3} \mathrm{~N}(250 \mu \mathrm{L}$, $1.8 \mathrm{mmol}$ ), and $\mathrm{LiCl}(50 \mathrm{mg}, 1.2 \mathrm{mmol})$ were added and stirred in $\mathrm{EtOH} / \mathrm{H}_{2} \mathrm{O}(3: 1)$ mixture $(100 \mathrm{~mL})$, and the reaction was heated at reflux for $5 \mathrm{~h}$ under Ar. A dark violet solution was hot filtered over Celite to remove insoluble starting material and by-products. The filtrate was rotary evaporated and purified by deactivated alumina column chromatography using $5 \%$ $\mathrm{MeOH} / \mathrm{DCM}$. The dark violet fraction was collected, and evaporated (465 mg, 69\%). ${ }^{1} \mathrm{H}$ NMR (500 MHz, $\left.\mathrm{CD}_{3} \mathrm{OD}\right): \delta 10.00$ (d, $J=5.7 \mathrm{~Hz}, 1 \mathrm{H}, \mathrm{B} 6), 8.68$ (s, 1H, B3), $8.63(\mathrm{~d}, J=8.2 \mathrm{~Hz}, 2 \mathrm{H}$, T3'), 8.52 (d, $J=8.0 \mathrm{~Hz}, 2 \mathrm{H}, \mathrm{T} 6), 8.40\left(\mathrm{~s}, 1 \mathrm{H}, \mathrm{B} 3^{\prime}\right), 8.08(\mathrm{t}, J=8.1$ $\left.\mathrm{Hz}, 1 \mathrm{H}, \mathrm{T} 4^{\prime}\right), 7.89$ (td, $\left.J=7.8,1.5 \mathrm{~Hz}, 2 \mathrm{H}, \mathrm{T} 5\right), 7.86(\mathrm{dd}, J=5.8$, $1.8 \mathrm{~Hz}, 1 \mathrm{H}, \mathrm{B} 5), 7.72$ (d, $J=5.5 \mathrm{~Hz}, 2 \mathrm{H}, \mathrm{T} 3), 7.33$ (ddd, $J=7.2$, $5.5,1.3 \mathrm{~Hz}, 2 \mathrm{H}, \mathrm{T} 4), 7.11$ (d, $\left.J=6.0 \mathrm{~Hz}, 1 \mathrm{H}, \mathrm{B} 66^{\prime}\right), 6.87$ (dd, $J=$ 6.1, $1.8 \mathrm{~Hz}, 1 \mathrm{H}, \mathrm{B} 5$ '), 2.81 (s, 3H, B7), $2.37 \mathrm{ppm}$ (s, 3H, B7'). ${ }^{13} \mathrm{C}$ NMR (500 MHz, CD 3 OD): $\delta 160.3$ (s, T2), 159.7 (s, T2'), 159.2 (s, B2), 157.2 (s, B2'), 153.2 (s, T3), 152.7 (s, B6), 151.9 (s, B6'), 150.5, (s, B4), 149.6 (s, B4'), 138.2 (s, T5), 135.0 (s, T4'), 129.0 (s, B5), 128.5 (s, T4), 128.4 (s, B5'), 125.4 (s, B3), 125.3 (s, B3'), 124.7 (s, T6), 123.6 (s, T3'), 21.4 (s, B7), 20.8 ppm (s, B7'). MS: $\mathrm{m} / \mathrm{z}$ 554.1, $[\mathrm{M}-\mathrm{Cl}]^{+}$(calc.: 554.1). Crystal growing: vapor diffusion of diethyl ether into a solution of $[\mathbf{1}] \mathrm{Cl}$ in ethanol.

$[\mathbf{R u}(\mathbf{t p y})(\mathbf{t f m b p y}) \mathbf{C l}] \mathbf{C l} \quad([2] \mathrm{Cl}) . \quad\left[\mathrm{Ru}(\mathrm{tpy}) \mathrm{Cl}_{3}\right] \quad(370 \quad \mathrm{mg}$, $0.85 \mathrm{mmol}$ ), 4,4'-tfmbpy (3) (250 mg, $0.85 \mathrm{mmol}), \mathrm{Et}_{3} \mathrm{~N}$ (188 $\mu \mathrm{L}, 1.35 \mathrm{mmol})$, and $\mathrm{LiCl}(39 \mathrm{mg}, 0.93 \mathrm{mmol})$ were added and stirred in $\mathrm{EtOH} / \mathrm{H}_{2} \mathrm{O}(3: 1)$ mixture $(140 \mathrm{~mL})$, and the reaction was heated at $100{ }^{\circ} \mathrm{C}$ for $4 \mathrm{~h}$ under Ar. A dark violet solution was hot filtered over Celite to remove insoluble starting material and by-products. The filtrate was rotary evaporated and purified by deactivated alumina column chromatography using 5\% MeOH/DCM. The solvent was evaporated to yield dark violet solid. It was redissolved in minimal amount of $\mathrm{MeOH}$, and precipitated with ether (417 mg, 71\%). The $\mathrm{PF}_{6}$ salt of the complex, $[2] \mathrm{PF}_{6}$, was made by dissolving [2] $\mathrm{Cl}$ in a minimal amount of $\mathrm{MeOH}$ and stirring with a $\mathrm{KPF}_{6}$ saturated aqueous solution for $3 \mathrm{~h}$. The solution was filtered and washed with water and ether. ${ }^{1} \mathrm{H}$ NMR (300 MHz, $\left.\mathrm{CD}_{3} \mathrm{OD}\right)$ : $\delta 10.49$ (d, $J=6.0 \mathrm{~Hz}, 1 \mathrm{H}, \mathrm{B} 6), 9.35$ (s, 1H, B3), 9.08 (s, 1H, B3'), $8.71\left(\mathrm{~d}, J=8.1 \mathrm{~Hz}, 2 \mathrm{H}, \mathrm{T} 3^{\prime}\right), 8.57$ (d, $\left.J=8.1 \mathrm{~Hz}, 2 \mathrm{H}, \mathrm{T} 6\right), 8.33$ (dd, $J=6.0,1.8 \mathrm{~Hz}, 1 \mathrm{H}, \mathrm{B} 5), 8.25$ (t, $\left.J=8.1 \mathrm{~Hz}, 1 \mathrm{H}, \mathrm{T} 4^{\prime}\right), 7.97$ (td, $J=7.9,1.5 \mathrm{~Hz}, 2 \mathrm{H}, \mathrm{T} 5), 7.80$ (d, $\left.J=6.0 \mathrm{~Hz}, 1 \mathrm{H}, \mathrm{B}^{\prime}\right), 7.68$ (d, $J=5.2 \mathrm{~Hz}, 2 \mathrm{H}, \mathrm{T} 3), 7.44-7.26 \mathrm{ppm}\left(\mathrm{m}, 3 \mathrm{H}, \mathrm{B}^{\prime}+\mathrm{T} 4\right) .{ }^{13} \mathrm{C}$ NMR (500 MHz, CD 3 OD): $\delta 161.4$ (s, B2), 159.9 (s, T2), 158.78 
(s, T2'), 158.7 (s, B2'), 155.0 (s, B6), 154.6 (s, B6'), 153.7 (s, T3), 139.0 (s, T5), 138.8 (q, $\left.{ }^{2} J_{\mathrm{CF}}=35.2 \mathrm{~Hz}, \mathrm{~B} 4\right), 137.6$ (q, ${ }^{2} J_{\mathrm{CF}}=35.2$ Hz, B4'), 136.8 (s, T4'), 128.7 (s, T4), 125.1 (s, T6), 125.1 (q, ${ }^{1} J_{\mathrm{CF}}$ $=73.2 \mathrm{~Hz}, \mathrm{~B} 7), 124.2$ (q, $\left.{ }^{3} J_{\mathrm{CF}}=3.8 \mathrm{~Hz}, \mathrm{~B} 5\right), 124.1\left(\mathrm{~s}, \mathrm{~T} 3{ }^{\prime}\right), 123.5$ $\left(\mathrm{q},{ }^{3} J_{\mathrm{CF}}=3.7 \mathrm{~Hz}, \mathrm{~B} 5^{\prime}\right), 122.9\left(\mathrm{q},{ }^{1} J=72.7 \mathrm{~Hz}, \mathrm{~B} 7^{\prime}\right), 122.0\left(\mathrm{q},{ }^{3} J=\right.$ $3.8 \mathrm{~Hz}, \mathrm{~B} 3), 121.6 \mathrm{ppm}\left(\mathrm{q},{ }^{3} J=3.8 \mathrm{~Hz}, \mathrm{~B} 3{ }^{\prime}\right) .{ }^{19} \mathrm{~F}\left\{{ }^{1} \mathrm{H}\right\}$ NMR (500 MHz, $\left.\mathrm{CD}_{3} \mathrm{OD}\right): \delta-65.6,-66.1 \mathrm{ppm}$. MS: $\mathrm{m} / z$ 662.0, [M $\mathrm{Cl}]^{+}$(calc.: 662.0). Crystal growing: vapor diffusion of diethyl ether into a solution of $[2]\left(\mathrm{PF}_{6}\right)$ in acetone. Elemental analysis calcd (\%) for $\mathrm{C}_{27} \mathrm{H}_{17} \mathrm{Cl}_{2} \mathrm{~F}_{6} \mathrm{~N}_{5} \mathrm{Ru} \cdot 1.5 \mathrm{H}_{2} \mathrm{O}$ : C 44.76 H 2.78 N 9.67; found: $\mathrm{C} 44.89 \mathrm{H} 2.79 \mathrm{~N} 9.67$.

$\left[\mathbf{R u}(\right.$ tpy $\left.)(\mathbf{d m b p y})\left(\mathbf{O H}_{2}\right)\right]\left(\mathbf{P F}_{\mathbf{6}}\right)_{\mathbf{2}}\left([\mathbf{3}]\left(\mathbf{P F}_{\mathbf{6}}\right)_{2}\right)$. The complex $[\mathbf{1}] \mathrm{Cl}$ (25 mg, $0.0424 \mathrm{mmol}$ ) was dissolved in $16 \mathrm{~mL}$ of acetone/water (3: 5), and $\mathrm{AgPF}_{6}(23.6 \mathrm{mg}, 0.0933 \mathrm{mmol}$ ) was added. The reaction was refluxed at $80^{\circ} \mathrm{C}$ for $3 \mathrm{~h}$ under Ar. It was filtered over Celite and the solvent was rotary evaporated. It was dissolved in minimal amount of acetone and precipitated with ether (24 mg, 69\%). ${ }^{1} \mathrm{H}$ NMR (300 MHz, $\left.\left(\mathrm{CD}_{3}\right)_{2} \mathrm{CO}\right): \delta 9.39$ (d, $J=5.7 \mathrm{~Hz}$, 1H, B6), 8.78-8.65 (m, 3H, T3' + B3), 8.57 (d, $J=8.1 \mathrm{~Hz}, 2 \mathrm{H}$, T6), 8.38 (s, 1H, B3'), 8.20 (t, $\left.J=8.1 \mathrm{~Hz}, 1 \mathrm{H}, \mathrm{T} 4^{\prime}\right), 8.07-7.92(\mathrm{~m}$, $3 \mathrm{H}, \mathrm{T} 5+\mathrm{B} 5), 7.73(\mathrm{~d}, J=5.4 \mathrm{~Hz}, 2 \mathrm{H}, \mathrm{T} 3), 7.37(\mathrm{t}, J=6.7 \mathrm{~Hz}, 2 \mathrm{H}$, T4), 7.14 (d, $\left.J=5.9 \mathrm{~Hz}, 1 \mathrm{H}, \mathrm{B} 6^{\prime}\right), 6.85$ (d, $J=6.0 \mathrm{~Hz}, 1 \mathrm{H}, \mathrm{B}^{\prime}$ ), 2.77 (s, 3H, B7), $2.30 \mathrm{ppm}\left(\mathrm{s}, 3 \mathrm{H}, \mathrm{B} 7^{\prime}\right) . \mathrm{MS}: \mathrm{m} / \mathrm{z} 268.4[\mathrm{M}-$ $\left.2 \mathrm{PF}_{6}\right]^{2+}$ (calc.: 268.6); $259.5\left[\mathrm{M}-2 \mathrm{PF}_{6}-\mathrm{H}_{2} \mathrm{O}\right]^{2+}$ (calc.: 259.6); $538.2[\mathrm{Ru}-\mathrm{O}-\mathrm{Ru} \text { dimer }+\mathrm{Na}]^{2+}$ (calc.: 538.1).

$\left[\mathbf{R u}(\right.$ tpy $\left.)(\mathbf{t f m b p y})\left(\mathbf{O H}_{2}\right)\right]\left(\mathbf{P F}_{\mathbf{6}}\right)_{\mathbf{2}}\left([\mathbf{4}]\left(\mathbf{P F}_{\mathbf{6}}\right)_{2}\right)$. The complex $[2] \mathrm{Cl}$ (30 mg, $0.0434 \mathrm{mmol}$ ), and $\mathrm{AgPF}_{6}(33 \mathrm{mg}, 0.130 \mathrm{mmol}$ ) were added to $5 \mathrm{~mL}$ of water in a microwave vial. The vial was purged with Ar for $20 \mathrm{~min}$. The mixture was heated by microwave at $140{ }^{\circ} \mathrm{C}$ for $10 \mathrm{~min}$. Some of the starting complex did not react and suspended in the red solution, so the reaction was heated again at $140{ }^{\circ} \mathrm{C}$ for another $10 \mathrm{~min}$. DCM and more water were added in order to extract the product. The product dissolved in the water phase and the starting complex dissolved in organic phase. Approximately $170 \mathrm{~mL}$ total was used for each phase for extraction. The water phase was filtered over Celite to filter away insoluble by-products. The water was rotary evaporated to yield a dark red solid (15 mg, 36\%). ${ }^{1} \mathrm{H}$ NMR $\left(300 \mathrm{MHz},\left(\mathrm{CD}_{3}\right)_{2} \mathrm{CO}\right): \delta 10.15(\mathrm{~d}, J=5.9 \mathrm{~Hz}, 1 \mathrm{H}, \mathrm{B} 6), 9.54(\mathrm{~s}$, 1H, B3), 9.22 (s, 1H, B3'), 8.91 (d, $\left.J=8.2 \mathrm{~Hz}, 2 \mathrm{H}, \mathrm{T} 3^{\prime}\right), 8.75$ (d, $J=8.0 \mathrm{~Hz}, 2 \mathrm{H}, \mathrm{T} 6), 8.54(\mathrm{~d}, J=6.0 \mathrm{~Hz}, 1 \mathrm{H}, \mathrm{B} 5), 8.48(\mathrm{t}, J=$ $\left.8.1 \mathrm{~Hz}, 1 \mathrm{H}, \mathrm{T} 44^{\prime}\right), 8.15$ (t, $\left.J=7.9 \mathrm{~Hz}, 2 \mathrm{H}, \mathrm{T} 5\right), 8.11$ (d, $J=6.1 \mathrm{~Hz}$, 1H, B6'), 8.06 (dd, $J=5.5 \mathrm{~Hz}, 2 \mathrm{H}, \mathrm{T} 3), 7.53-7.42 \mathrm{ppm}(\mathrm{m}, 3 \mathrm{H}$, $\left.\mathrm{B}^{\prime}+\mathrm{T} 4\right), 6.25\left(\mathrm{~s}, 2 \mathrm{H}, \mathrm{OH}_{2}\right.$ ). MS: $m / z 322.3\left[\mathrm{M}-2 \mathrm{PF}_{6}\right]^{2+}$ (calc.: 322.5); $313.2\left[\mathrm{M}-2 \mathrm{PF}_{6}-\mathrm{H}_{2} \mathrm{O}\right]^{2+}$ (calc.: 313.5); $646.1[\mathrm{Ru}-\mathrm{O}-$ $\mathrm{Ru}$ dimer $+\mathrm{Na}]^{2+}$ (calc.: 646.1).

$\left[\mathbf{R u}(\right.$ tpy $\left.)(\mathbf{d m b p y})\left(\mathbf{N C C H}_{3}\right)\right]\left(\mathbf{P F}_{\mathbf{6}}\right)_{\mathbf{2}}\left([\mathbf{5}]\left(\mathbf{P F}_{\mathbf{6}}\right)_{2}\right)$. The complex was synthesized using a modified literature procedure. ${ }^{30}$ Complex [1]Cl (49 mg, $0.083 \mathrm{mmol}$ ) was dissolved in $30 \mathrm{~mL}$ of acetonitrile, and the reaction was refluxed at $82{ }^{\circ} \mathrm{C}$ under $\mathrm{Ar}$. According to TLC (aluminum oxide, 5\% MeOH/DCM), no product was observed after $18 \mathrm{~h}$. To the mixture, 2.2 equivalents (46 mg, $0.182 \mathrm{mmol}$ ) of $\mathrm{AgPF}_{6}$ was added and refluxed for an additional $3 \mathrm{~h}$, resulting in a yellow compound on TLC along with starting material. To assist conversion to the aqua, $20 \mathrm{~mL}$ of distilled water was added to the reaction and refluxed for an additional 18 hours, which resulted in an orange suspension. The suspension was filtered over Celite, and washed with acetonitrile. The solvent was rotary evaporated. The solid was dissolved in minimal amount of acetonitrile, then precipitated with ether, and filtered (47 mg, 67\%). ${ }^{1} \mathrm{H}$ NMR spectrum in $\mathrm{CD}_{3} \mathrm{CN}$ corresponded to literature. ${ }^{30}{ }^{1} \mathrm{H}$ NMR $(300 \mathrm{MHz}$, $\left.\left(\mathrm{CD}_{3}\right)_{2} \mathrm{CO}\right): \delta 9.69(\mathrm{~d}, J=5.7 \mathrm{~Hz}, 1 \mathrm{H}, \mathrm{B} 6), 8.85(\mathrm{~d}, J=8.1 \mathrm{~Hz}, 2 \mathrm{H}$, T3'), 8.79 (s, 1H, B3), 8.72 (d, J = 8.1 Hz, 2H, T6), 8.54 (s, 1H, B3'), $8.43\left(\mathrm{t}, J=8.1 \mathrm{~Hz}, 1 \mathrm{H}, \mathrm{T}^{\prime}\right), 8.14(\mathrm{td}, J=7.9,1.5 \mathrm{~Hz}, 2 \mathrm{H}$, T5), 7.97 (dd, $J=5.4,1.5 \mathrm{~Hz}, 2 \mathrm{H}, \mathrm{T} 3), 7.92(\mathrm{dd}, J=5.9,1.7 \mathrm{~Hz}$, 1H, B5), 7.52 (ddd, $J=7.4,5.6,1.3 \mathrm{~Hz}, 2 \mathrm{H}, \mathrm{T} 4), 7.39$ (d, $J=$ $\left.5.8 \mathrm{~Hz}, 1 \mathrm{H}, \mathrm{B6} 6^{\prime}\right), 7.06$ (d, $\left.J=5.6 \mathrm{~Hz}, 1 \mathrm{H}, \mathrm{B} 55^{\prime}\right), 2.79$ (s, 3H, B7), 2.40 (s, 3H, B7'), $2.30 \mathrm{ppm}\left(\mathrm{s}, 3 \mathrm{H}, \mathrm{CH}_{3}-\mathrm{CN}\right.$ ). MS: $\mathrm{m} / z 279.8$ $\left[\mathrm{M}-2 \mathrm{PF}_{6}\right]^{2+}$ (calc.: 280.1); 705.2 $\left[\mathrm{M}-\mathrm{PF}_{6}\right]^{+}$(calc.: 705.1). Crystal growing: vapor diffusion of toluene into a solution of $[5]\left(\mathrm{PF}_{6}\right)_{2}$ in acetonitrile.

$\left[\mathbf{R u}(\mathbf{t p y})(\mathbf{t f m b p y})\left(\mathbf{N C C H}_{3}\right)\right]\left(\mathbf{P F}_{\mathbf{6}}\right)_{\mathbf{2}} \quad\left([\mathbf{6}]\left(\mathbf{P F}_{\mathbf{6}}\right)_{2}\right)$. The complex [2]Cl (25 mg, $0.036 \mathrm{mmol}$ ) was dissolved in 1:1 mixture of acetonitrile and water $(50 \mathrm{~mL})$, and $\mathrm{AgPF}_{6}(20 \mathrm{mg}, 0.079 \mathrm{mmol})$ was added. The reaction was refluxed at $82{ }^{\circ} \mathrm{C}$ under $\mathrm{Ar}$ for $17 \mathrm{~h}$. The orange solution was filtered over Celite, and the solvent was rotary evaporated. The solid was dissolved in minimal amount of acetonitrile, then precipitated with ether, and filtered (25 mg, 73\%). ${ }^{1} \mathrm{H}$ NMR (300 MHz, $\left.\left(\mathrm{CD}_{3}\right)_{2} \mathrm{CO}\right)$ : $\delta 10.24$ (d, $J=5.9 \mathrm{~Hz}, 1 \mathrm{H}, \mathrm{B} 6), 9.51$ (s, 1H, B3), 9.27 (s, 1H, B3'), $8.90\left(\mathrm{~d}, J=8.1 \mathrm{~Hz}, 2 \mathrm{H}, \mathrm{T} 3^{\prime}\right), 8.73(\mathrm{~d}, J=8.1 \mathrm{~Hz}, 2 \mathrm{H}, \mathrm{T} 6), 8.53(\mathrm{t}$, $\left.J=8.1 \mathrm{~Hz}, 1 \mathrm{H}, \mathrm{T} 4^{\prime}\right), 8.39$ (dd, $\left.J=6.0,1.8 \mathrm{~Hz}, 1 \mathrm{H}, \mathrm{B} 5\right), 8.17$ (td, $J=7.9,1.5 \mathrm{~Hz}, 2 \mathrm{H}, \mathrm{T} 5), 8.07$ (d, $\left.J=6.0 \mathrm{~Hz}, 1 \mathrm{H}, \mathrm{B} 6^{\prime}\right), 8.03(\mathrm{dd}, J=$ 5.5, 1.4 Hz, 2H, T3), 7.57 (d, $J=6.0,1.9 \mathrm{~Hz}, 1 \mathrm{H}, \mathrm{B}^{\prime}$ ), 7.49 (ddd, $J=7.2,5.5,1.3 \mathrm{~Hz}, 2 \mathrm{H}, \mathrm{T} 4), 2.33 \mathrm{ppm}\left(\mathrm{s}, 3 \mathrm{H}, \mathrm{CH}_{3}-\mathrm{CN}\right) . \mathrm{MS}: \mathrm{m} / z$ $333.7\left[\mathrm{M}-2 \mathrm{PF}_{6}\right]^{2+}$ (calc.: 334.0); 813.2 [M - $\left.\mathrm{PF}_{6}\right]^{+}$(calc.: 813.0). Crystal growing: vapor diffusion of diethyl ether into a solution of $[6]\left(\mathrm{PF}_{6}\right)_{2}$ in acetonitrile. Elemental analysis calcd (\%) for $\mathrm{C}_{29} \mathrm{H}_{20} \mathrm{~F}_{18} \mathrm{~N}_{6} \mathrm{P}_{2} \mathrm{Ru} \cdot 0.5 \mathrm{H}_{2} \mathrm{O} \cdot 0.5 \mathrm{C}_{3} \mathrm{H}_{6} \mathrm{O} \cdot 0.5 \mathrm{CH}_{3} \mathrm{CN}$ : C $37.24 \mathrm{H} 2.53$ $\mathrm{N}$ 8.96; found: C $37.16 \mathrm{H} 2.55 \mathrm{~N} 8.97$.

$[\mathbf{R u}(\mathbf{t p y})(\mathbf{d m b p y})(\mathbf{H m t e})]\left(\mathbf{P F}_{\mathbf{6}}\right)_{\mathbf{2}} \quad\left([7]\left(\mathbf{P F}_{\mathbf{6}}\right)_{2}\right)$. The complex [3] $\left(\mathrm{PF}_{6}\right)_{2}(28 \mathrm{mg}, 0.034 \mathrm{mmol})$ was dissolved in $16 \mathrm{~mL}$ of mixture of acetone and water $(3: 5)$, and 2 -(methylthio)ethanol $(30 \mu \mathrm{L}$, $0.34 \mathrm{mmol}$ ) was added. The reaction was refluxed at $80{ }^{\circ} \mathrm{C}$ under Ar for $21 \mathrm{~h}$. The orange solution was rotary evaporated, redissolved in minimal amount of acetone, and then precipitated with ether. It was filtered to yield orange solid (19 mg, $62 \%) .{ }^{1} \mathrm{H}$ NMR (300 MHz, $\left.\left(\mathrm{CD}_{3}\right)_{2} \mathrm{CO}\right): \delta 9.72(\mathrm{~d}, J=5.8 \mathrm{~Hz}, 1 \mathrm{H}$, B6), 8.89 (d, $\left.J=8.2 \mathrm{~Hz}, 2 \mathrm{H}, \mathrm{T} 3^{\prime}\right), 8.80$ (s, 1H, B3), 8.74 (d, $J=$ $8.1 \mathrm{~Hz}, 2 \mathrm{H}, \mathrm{T} 6), 8.57$ (s, 1H, B3'), 8.47 (t, $J=8.1 \mathrm{~Hz}, 1 \mathrm{H}, \mathrm{T}^{\prime}$ ), $8.17(\mathrm{td}, J=7.9,1.5 \mathrm{~Hz}, 2 \mathrm{H}, \mathrm{T} 5), 8.01$ (d, $J=5.0 \mathrm{~Hz}, 2 \mathrm{H}, \mathrm{T} 3)$, $7.96(\mathrm{dd}, J=5.9,1.7 \mathrm{~Hz}, 1 \mathrm{H}, \mathrm{B} 5), 7.54(\mathrm{ddd}, J=7.4,5.6,1.3 \mathrm{~Hz}$, 2H, T4), 7.33 (d, $\left.J=5.8 \mathrm{~Hz}, 1 \mathrm{H}, \mathrm{B} 6^{\prime}\right), 7.11$ (dd, $J=5.5,1.6 \mathrm{~Hz}$, 1H, B5'), 3.53 (t, $5.7 \mathrm{~Hz}, 2 \mathrm{H},-\mathrm{S}-\mathrm{CH}_{2}-\mathrm{CH}_{2}-$ ), 2.78 (s, 3H, B7), 2.40 (s, 3H, B7'), 1.97 (t, $5.7 \mathrm{~Hz}, 2 \mathrm{H},-\mathrm{S}-\mathrm{CH}_{2}-\mathrm{CH}_{2}-$ ), $1.50 \mathrm{ppm}$ (s, 3H, $\mathrm{CH}_{3}-\mathrm{S}-$ ). MS: $\mathrm{m} / z$ 305.3 $\left[\mathrm{M}-2 \mathrm{PF}_{6}\right]^{2+}$ (calc.: 305.6); $756.2\left[\mathrm{M}-\mathrm{PF}_{6}\right]^{+}$(calc.: 756.1). Crystal growing: vapor diffusion of diethyl ether into a solution of $[7]\left(\mathrm{PF}_{6}\right)_{2}$ in acetone. Elemental analysis calcd (\%) for $\mathrm{C}_{30} \mathrm{H}_{31} \mathrm{~F}_{12} \mathrm{~N}_{5} \mathrm{OP}_{2} \mathrm{RuS} \cdot 2$ $\mathrm{H}_{2} \mathrm{O} \cdot 0.75 \mathrm{C}_{3} \mathrm{H}_{6} \mathrm{O} \cdot 0.25 \mathrm{PF}_{6}$ : $\mathrm{C} 38.11 \mathrm{H} 3.92 \mathrm{~N}$ 6.89; found: C 38.19 H 3.92 N 6.97 . 
$\left[\mathbf{R u}(\right.$ tpy $)($ tfmbpy)$(\mathrm{Hmte})]\left(\mathbf{P F}_{\mathbf{6}}\right)_{2}\left([\mathbf{8}]\left(\mathbf{P F}_{\mathbf{6}}\right)_{2}\right)$. The complex [2]Cl (27 mg, $0.0383 \mathrm{mmol}$ ) was dissolved in $16 \mathrm{~mL}$ of mixture of acetone and water $(3: 5)$, and 2 -(methylthio)ethanol $(33 \mu \mathrm{L}$, $0.38 \mathrm{mmol}$ ), and $\mathrm{AgPF}_{6}(21 \mathrm{mg}, 0.084 \mathrm{mmol})$ were added. The reaction was refluxed at $80^{\circ} \mathrm{C}$ for $22 \mathrm{~h}$. The reaction mixture was filtered over Celite and the solvent was rotary evaporated. According to ${ }^{1} \mathrm{H}$ NMR, there seemed to be more than one species. Therefore, the crude product was dissolved in $16 \mathrm{~mL}$ of acetone/water (3:5), the same amount of $\mathrm{AgPF}_{6}$ and $100 \mu \mathrm{L}$ of 2-(methylthio)ethanol were added, and the reaction was refluxed at $80{ }^{\circ} \mathrm{C}$ under $\mathrm{Ar}$ for $24 \mathrm{~h}$. The orange solution was again filtered over Celite, and the solvent was removed (32 mg, 82\%). ${ }^{1} \mathrm{H}$ NMR (400 MHz, $\left.\left(\mathrm{CD}_{3}\right)_{2} \mathrm{CO}\right): \delta 10.36$ (d, $J=$ $5.9 \mathrm{~Hz}, 1 \mathrm{H}, \mathrm{B} 6), 9.53$ (s, 1H, B3), 9.33 (s, 1H, B3'), 8.99 (d, $J=$ $\left.8.2 \mathrm{~Hz}, 2 \mathrm{H}, \mathrm{T} 3^{\prime}\right), 8.81(\mathrm{dd}, J=8.1,1.2 \mathrm{~Hz}, 2 \mathrm{H}, \mathrm{T} 6), 8.57$ (t, $J=$ $\left.8.1 \mathrm{~Hz}, 1 \mathrm{H}, \mathrm{T} 4^{\prime}\right), 8.52(\mathrm{dd}, J=6.1,1.9 \mathrm{~Hz}, 1 \mathrm{H}, \mathrm{B} 5), 8.19(\mathrm{td}, J=$ 7.9, $1.5 \mathrm{~Hz}, 2 \mathrm{H}, \mathrm{T}$ ), 8.10 (dd, $J=5.5,1.6 \mathrm{~Hz}, 2 \mathrm{H}, \mathrm{T} 3), 7.99$ (d, $\left.J=5.9 \mathrm{~Hz}, 1 \mathrm{H}, \mathrm{B6} 6^{\prime}\right), 7.63\left(\mathrm{dd}, J=5.9,1.9 \mathrm{~Hz}, 1 \mathrm{H}, \mathrm{B} 5^{\prime}\right)$, 7.50 (ddd, $J=7.7,5.5,1.3 \mathrm{~Hz}, 2 \mathrm{H}, \mathrm{T} 4), 4.83(\mathrm{t}, J=5.5 \mathrm{~Hz}, 1 \mathrm{H}$, $-\mathrm{OH}), 3.53\left(\mathrm{td}, J=5.5 \mathrm{~Hz}, 2 \mathrm{H},-\mathrm{CH}_{2}-\mathrm{OH}\right), 2.10(\mathrm{t}, J=5.7 \mathrm{~Hz}$, $2 \mathrm{H},-\mathrm{S}-\mathrm{CH}_{2}-$ ), $1.52 \mathrm{ppm}\left(\mathrm{s}, 3 \mathrm{H}, \mathrm{CH}_{3}-\mathrm{S}-\right.$ ). MS: $\mathrm{m} / \mathrm{z} 359.1$ [M $\left.2 \mathrm{PF}_{6}\right]^{2+}$ (calc.: 359.5 ); $864.2\left[\mathrm{M}-\mathrm{PF}_{6}\right]^{+}$(calc.: 864.0 ). Crystal growing: vapor diffusion of diethyl ether into a solution of $[8]\left(\mathrm{PF}_{6}\right)_{2}$ in ethanol. Elemental analysis calcd (\%) for $\mathrm{C}_{30} \mathrm{H}_{25} \mathrm{~F}_{18} \mathrm{~N}_{5} \mathrm{OP}_{2}$ RuS: C $35.73 \mathrm{H} 2.50 \mathrm{~N}$ 6.94; found: $\mathrm{C} 35.78 \mathrm{H}$ $2.52 \mathrm{~N} 6.83$.

$[\mathbf{R u}($ tpy $)(\mathbf{d m b p y})(\mathbf{p y})]\left(\mathrm{PF}_{6}\right)_{2}\left([9]\left(\mathrm{PF}_{6}\right)_{2}\right)$. The complex $[3]\left(\mathrm{PF}_{6}\right)_{2}$ (41 mg, $0.05 \mathrm{mmol}$ ) was dissolved in $20 \mathrm{~mL}$ of ethanol/water $(1: 1)$, and excess amount of pyridine $(1 \mathrm{~mL})$ was added. The reaction was refluxed at $80{ }^{\circ} \mathrm{C}$ under $\mathrm{Ar}$ for $24 \mathrm{~h}$. Ethanol was rotary evaporated, and then saturated $\mathrm{KPF}_{6}$ aqueous solution was added. After the mixture was stirred, the dark orange precipitate was filtered and washed with water and ether. According to ${ }^{1} \mathrm{H}$ NMR in $\left(\mathrm{CD}_{3}\right)_{2} \mathrm{CO}$, the product still had pyridine. The crude product was dissolved in minimal amount of acetone, precipitated with ether, and filtered $(23 \mathrm{mg}, 51 \%) .{ }^{1} \mathrm{H}$ NMR spectrum in $\mathrm{CD}_{3} \mathrm{CN}$ corresponded to literature. ${ }^{47}{ }^{1} \mathrm{H}$ NMR (300 MHz, $\left.\left(\mathrm{CD}_{3}\right)_{2} \mathrm{CO}\right): \delta 8.83\left(\mathrm{~m}, 3 \mathrm{H}, \mathrm{B} 3+\mathrm{T} 3^{\prime}\right), 8.76(\mathrm{~d}$, $J=5.9 \mathrm{~Hz}, 1 \mathrm{H}, \mathrm{B} 6), 8.73(\mathrm{~d}, J=8.1 \mathrm{~Hz}, 2 \mathrm{H}, \mathrm{T6}), 8.58\left(\mathrm{~s}, 1 \mathrm{H}, \mathrm{B} 3^{\prime}\right)$, $8.34\left(\mathrm{t}, J=8.1 \mathrm{~Hz}, 1 \mathrm{H}, \mathrm{T} 4^{\prime}\right), 8.17(\mathrm{td}, J=7.9,1.5 \mathrm{~Hz}, 2 \mathrm{H}, \mathrm{T} 5)$, $8.12(\mathrm{~d}, J=5.4,1.6 \mathrm{~Hz}, 2 \mathrm{H}, \mathrm{T} 3), 8.02(\mathrm{dd}, J=6.5,1.6 \mathrm{~Hz}, 2 \mathrm{H}$, P2), 7.89 (tt, $J=7.7,1.6 \mathrm{~Hz}, 1 \mathrm{H}, \mathrm{P} 4), 7.84$ (d, $J=5.8 \mathrm{~Hz}, 1 \mathrm{H}$, B5), 7.59 (ddd, $J=7.4,5.6,1.3 \mathrm{~Hz}, 2 \mathrm{H}, \mathrm{T} 4), 7.41(\mathrm{~d}, J=5.8 \mathrm{~Hz}$, $\left.1 \mathrm{H}, \mathrm{B}^{\prime}\right), 7.34(\mathrm{t}, J=6.5 \mathrm{~Hz}, 2 \mathrm{H}, \mathrm{P} 3), 7.06(\mathrm{dd}, J=5.5,1.6 \mathrm{~Hz}$, 1H, B5'), 2.77 (s, 3H, B7), $2.41 \mathrm{ppm}$ (s, 3H, B7'). MS: $m / z 298.9$ $\left[\mathrm{M}-2 \mathrm{PF}_{6}\right]^{2+}$ (calc.: 299.1); $743.2\left[\mathrm{M}-\mathrm{PF}_{6}\right]^{+}$(calc.: 743.1). Crystal growing: vapor diffusion of toluene into a solution of $[9]\left(\mathrm{PF}_{6}\right)_{2}$ in acetone.

$[\mathbf{R u}($ tpy $)(\mathbf{t f m b p y})(\mathbf{p y})]\left(\mathrm{PF}_{6}\right)_{2} \quad\left([\mathbf{1 0}]\left(\mathbf{P F}_{6}\right)_{2}\right) . \quad$ The complex [4] $\left(\mathrm{PF}_{6}\right)_{2}(20 \mathrm{mg}, 0.022 \mathrm{mmol})$ was dissolved in $20 \mathrm{~mL}$ of ethanol/ water $(1: 1)$, and excess amount of pyridine $(1 \mathrm{~mL})$ was added. The reaction was refluxed at $80^{\circ} \mathrm{C}$ under $\mathrm{Ar}$ for $24 \mathrm{~h}$. After the solvent was rotary evaporated, the orange solid was dissolved in minimal amount of acetone, precipitated with ether, and filtered $(19.5 \mathrm{mg}, 90 \%) .{ }^{1} \mathrm{H}$ NMR $\left(300 \mathrm{MHz},\left(\mathrm{CD}_{3}\right)_{2} \mathrm{CO}\right): \delta 9.60(\mathrm{~s}$, 1H, B3), 9.36 (s, 1H, B3'), 9.34 (d, $J=4.8 \mathrm{~Hz}, 1 \mathrm{H}, \mathrm{B} 6), 8.96$ (d,
$\left.J=8.1 \mathrm{~Hz}, 2 \mathrm{H}, \mathrm{T} 3^{\prime}\right), 8.84(\mathrm{~d}, J=8.3 \mathrm{~Hz}, 2 \mathrm{H}, \mathrm{T} 6), 8.47(\mathrm{t}, J=$ $\left.8.1 \mathrm{~Hz}, 1 \mathrm{H}, \mathrm{T} 4^{\prime}\right), 8.35$ (d, $\left.J=6.1 \mathrm{~Hz}, 1 \mathrm{H}, \mathrm{B} 5\right), 8.27-8.17(\mathrm{~m}, 4 \mathrm{H}$, $\mathrm{T} 5+\mathrm{T} 3), 8.11\left(\mathrm{~d}, J=5.8 \mathrm{~Hz}, 3 \mathrm{H}, \mathrm{B} 6^{\prime}+\mathrm{P} 2\right), 7.96(\mathrm{t}, J=7.6 \mathrm{~Hz}$, $1 \mathrm{H}, \mathrm{P} 4), 7.64-7.50\left(\mathrm{~m}, 3 \mathrm{H}, \mathrm{B} 5^{\prime}+\mathrm{T} 4\right), 7.41 \mathrm{ppm}(\mathrm{t}, J=6.7 \mathrm{~Hz}$, 2H, P3). MS: $m / z 352.8\left[\mathrm{M}-2 \mathrm{PF}_{6}\right]^{2+}$ (calc.: 353.0). Crystal growing: vapor diffusion of toluene into a solution of [10] $\left(\mathrm{PF}_{6}\right)_{2}$ in acetone. Elemental analysis calcd (\%) for $\mathrm{C}_{32} \mathrm{H}_{22} \mathrm{~F}_{12} \mathrm{~N}_{6} \mathrm{P}_{2} \mathrm{Ru} \cdot 1.5 \quad \mathrm{H}_{2} \mathrm{O} \cdot 0.25 \quad \mathrm{C}_{3} \mathrm{H}_{6} \mathrm{O} \cdot 0.25 \quad \mathrm{PF}_{6} \cdot 0.25 \quad \mathrm{C}_{5} \mathrm{H}_{5} \mathrm{~N}$ : C $39.34 \mathrm{H} 2.75 \mathrm{~N}$ 8.51; found: C $39.40 \mathrm{H} 2.72 \mathrm{~N} 8.54$.

$\left[\mathbf{R u}(\mathbf{t f m b p y})_{3}\right] \mathbf{C l}_{2}$. The complex was synthesized using literature method. ${ }^{48}{ }^{1} \mathrm{H}$ NMR $\left(400 \mathrm{MHz},\left(\mathrm{CD}_{3}\right)_{2} \mathrm{CO}\right): \delta 9.44(\mathrm{~d}, J=1.9$ $\mathrm{Hz}, 1 \mathrm{H}, \mathrm{H} 3), 8.54$ (d, $J=5.9 \mathrm{~Hz}, 1 \mathrm{H}, \mathrm{H6}), 7.89 \mathrm{ppm}(\mathrm{dd}, J=5.9$, $1.8 \mathrm{~Hz}, 1 \mathrm{H}, \mathrm{H} 5)$. MS: $m / z$ 489.4 $[\mathrm{M}-2 \mathrm{Cl}]^{2+}$ (calc.: 489.0); $1013.0[\mathrm{M}-\mathrm{Cl}]^{+}$(calc.: 1013.0).

\section{Electrochemistry}

Cyclic voltammetry experiments were performed using a threeelectrode cell setup, which included a platinum working electrode, a silver wire pseudo reference electrode, and platinum wire auxiliary electrode. The supporting electrolyte was $0.1 \mathrm{M}$ tetrabutylammonium hexafluorophosphate $\left(\mathrm{Bu}_{4} \mathrm{NPF}_{6}\right)$ in $\mathrm{CH}_{3} \mathrm{CN}$. The final complex concentration was $1 \mathrm{mM}$. Prior to measurement, the solvent was purged with argon and was measured at room temperature using an Autolab PGSTAT10 potentiostat and GPES 4.9 program by Eco Chemie. Each CV experiment was referenced to the ferrocene oxidation potential.

\section{Emission quantum yields}

The quantum yield of ${ }^{3}$ MLCT emission was determined in a custom-built setup. All optical parts were connected using optical fibers from Avantes (Apeldoorn, The Netherlands), with a diameter of 200-600 $\mu \mathrm{m}$. The samples were measured in a $1 \mathrm{~cm}$ path length QS cuvette. For each measurement, $3 \mathrm{~mL}$ of sample consisting of the compound in acetonitrile $\left(\lambda_{\mathrm{abs}}^{450 \mathrm{~nm}}=\right.$ 0.1), was placed in a CUV-UV/VIS-TC temperature-controlled cuvette holder from Avantes. The sample was deoxygenated using nitrogen gas for $10 \mathrm{~min}$ while also equilibrating to $293 \mathrm{~K}$. Emission spectroscopy was performed with a $450 \mathrm{~nm}$ fiber-coupled laser (Laser system LRD-0450 from Laserglow, Toronto, Canada), which was set to $50 \mathrm{~mW}$ at the cuvette ( $4 \mathrm{~mm}$ beam diameter; $0.4 \mathrm{~W} \mathrm{~cm}^{-2}$ ) at a $90^{\circ}$ angle with respect to the spectrometer. The excitation power was measured using a S310C thermal sensor connected to a PM100USB power meter (Thorlabs). The emission spectrum was visualized from 500-800 nm with an Avantes 2048L StarLine UV-Vis spectrometer as detector. No difference in the electronic absorption spectrum (measured using a Varian Cary 50 UV-vis spectrometer) was found due to exposure to the $450 \mathrm{~nm}$ laser, showing that emission is from the starting compound. All emission spectra were recorded using Avasoft software from Avantes and further processed using Microsoft Office Excel 2010 and Origin Pro software.

The quantum yield of emission from the ${ }^{3}$ MLCT excited state was calculated using the relative method with $\left[\mathrm{Ru}(\mathrm{bpy})_{3}\right]$ 
$\mathrm{Cl}_{2}$ as the standard (0.06 in deoxygenated $\mathrm{CH}_{3} \mathrm{CN}$ ), according to eqn (2):

$$
\Phi_{\text {sample }}^{3 \mathrm{MLCT}}=\Phi_{\text {std }}^{3 \mathrm{MLCT}} \times \frac{A_{\text {std }}^{450}}{A_{\text {sample }}^{450}} \times \frac{E_{\text {sample }}}{E_{\text {std }}}
$$

where $\Phi^{3 \text { MLCT }}$ is the quantum yield of ${ }^{3}$ MLCT emission, $A^{450}$ is the absorbance at $450 \mathrm{~nm}$ (generally 0.1 for a $1 \mathrm{~cm}$ path length), $E$ is the integrated area of the ${ }^{3}$ MLCT emission band, and sample and std denote the sample and standard $\left(\left[\mathrm{Ru}(\mathrm{bpy})_{3}\right] \mathrm{Cl}_{2}\right)$, respectively.

\section{Photochemistry}

Photosubstitution experiments were performed using the setup described in literature, ${ }^{27}$ where a $490 \mathrm{~nm}$ LED lamp was fixed on top of a $1 \mathrm{~cm}$ quartz cuvette, and the temperature was controlled using a Peltier controller to maintain $25^{\circ} \mathrm{C}$ during the $30 \mathrm{~min}$ irradiation. The beginning concentration of the solutions was determined such that the absorbance at the irradiation wavelength $\left(\lambda_{\text {irr }}=490 \mathrm{~nm}\right)$ was approximately 0.5 . The photon flux of the $490 \mathrm{~nm}$ LED lamp was determined to be approximately $1.0 \times 10^{-7}$ Einstein $\mathrm{s}^{-1}$ by ferrioxalate actinometry. ${ }^{49}$ The specific photon flux and reaction conditions are referenced in each experiment. The concentrations were calculated using the two-wavelength method. ${ }^{27}$

\section{Acknowledgements}

The European Research Council is kindly acknowledged for a Starting Grant to S. B. This work was also supported by the Dutch Organization for Scientific Research (NWO) via a VIDI grant to S. B. Prof. E. Bouwman is kindly acknowledged for support and input.

\section{References}

1 S. Ardo and G. J. Meyer, Chem. Soc. Rev., 2009, 38, 115-164.

2 G. Li, W. M. Ward and G. J. Meyer, J. Am. Chem. Soc., 2015, 137, 8321-8323.

3 K. L. Skubi, T. R. Blum and T. P. Yoon, Chem. Rev., 2016, 116, 10035-10074.

4 M. D. Kärkäs, O. Verho, E. V. Johnston and B. Åkermark, Chem. Rev., 2014, 114, 11863-12001.

5 P. C. Ford and S. Wecksler, Coord. Chem. Rev., 2005, 249, 1382-1395.

6 C. Mari, V. Pierroz, S. Ferrari and G. Gasser, Chem. Sci., 2015, 6, 2660-2686.

7 B. M. Blunden and M. H. Stenzel, J. Chem. Technol. Biotechnol., 2015, 90, 1177-1195.

8 R. N. Garner, J. C. Gallucci, K. R. Dunbar and C. Turro, Inorg. Chem., 2011, 50, 9213-9215.

9 M. Frasconi, Z. Liu, J. Lei, Y. Wu, E. Strekalova, D. Malin, M. W. Ambrogio, X. Chen, Y. Y. Botros, V. L. Cryns, J.-P. Sauvage and J. F. Stoddart, J. Am. Chem. Soc., 2013, 135, 11603-11613.
10 A. N. Hidayatullah, E. Wachter, D. K. Heidary, S. Parkin and E. C. Glazer, Inorg. Chem., 2014, 53, 10030-10032.

11 B. Siewert, V. H. S. van Rixel, E. J. van Rooden, S. L. Hopkins, M. J. B. Moester, F. Ariese, M. A. Siegler and S. Bonnet, Chem. - Eur. J., 2016, 22, 10960-10968.

12 L. N. Lameijer, S. L. Hopkins, T. G. Brevé, S. H. C. Askes and S. Bonnet, Chem. - Eur. J., 2016, 22, 18484-18491.

13 P. S. Wagenknecht and P. C. Ford, Coord. Chem. Rev., 2011, 255, 591-616.

14 S. Bonnet and J.-P. Collin, Chem. Soc. Rev., 2008, 37, 12071217.

15 P. A. Scattergood, U. Khushnood, A. Tariq, D. J. Cooke, C. R. Rice and P. I. P. Elliott, Inorg. Chem., 2016, 55, 77877796.

16 Q. Sun, B. Dereka, E. Vauthey, L. M. Lawson Daku and A. Hauser, Chem. Sci., 2017, 8, 223-230.

17 Q. Sun, S. Mosquera-Vazquez, L. M. Lawson Daku, L. Guénée, H. A. Goodwin, E. Vauthey and A. Hauser, J. Am. Chem. Soc., 2013, 135, 13660-13663.

18 Q. Sun, S. Mosquera-Vazquez, Y. Suffren, J. Hankache, N. Amstutz, L. M. Lawson Daku, E. Vauthey and A. Hauser, Coord. Chem. Rev., 2015, 282-283, 87-99.

19 C. E. Welby, G. K. Armitage, H. Bartley, A. Wilkinson, A. Sinopoli, B. S. Uppal, C. R. Rice and P. I. P. Elliott, Chem. - Eur. J., 2014, 20, 8467-8476.

20 C. E. Welby, C. R. Rice and P. I. P. Elliott, Angew. Chem., Int. Ed., 2013, 52, 10826-10829.

21 J. K. White, R. H. Schmehl and C. Turro, Inorg. Chim. Acta, 2017, 454, 7-20.

22 A. J. Göttle, F. Alary, M. Boggio-Pasqua, I. M. Dixon, J.-L. Heully, A. Bahreman, S. H. C. Askes and S. Bonnet, Inorg. Chem., 2016, 55, 4448-4456.

23 S. Bonnet, J.-P. Collin, J.-P. Sauvage and E. Schofield, Inorg. Chem., 2004, 43, 8346-8354.

24 J. D. Knoll, B. A. Albani and C. Turro, Chem. Commun., 2015, 51, 8777-8780.

25 J. D. Knoll, B. A. Albani, C. B. Durr and C. Turro, J. Phys. Chem. A, 2014, 118, 10603-10610.

26 B. A. Albani, T. Whittemore, C. B. Durr and C. Turro, Photochem. Photobiol., 2015, 91, 616-623.

27 A. Bahreman, B. Limburg, M. A. Siegler, E. Bouwman and S. Bonnet, Inorg. Chem., 2013, 52, 9456-9469.

28 B. S. Howerton, D. K. Heidary and E. C. Glazer, J. Am. Chem. Soc., 2012, 134, 8324-8327.

29 R. N. Garner, L. E. Joyce and C. Turro, Inorg. Chem., 2011, 50, 4384-4391.

30 T. A. White, S. Maji and S. Ott, Dalton Trans., 2014, 43, 15028-15037.

31 K. Mikami, Y. Itoh and M. Yamanaka, Chem. Rev., 2004, 104, 1-16.

32 L.-Y. Liao, X.-R. Kong and X.-F. Duan, J. Org. Chem., 2014, 79, 777-782.

33 K. S. Chan and A. K. S. Tse, Synth. Commun., 1993, 23, 1929-1934.

34 J. Broomhead and F. Dwyer, Aust. J. Chem., 1961, 14, 250252. 
35 N. A. Eckert, E. M. Bones, R. J. Lachicotte and P. L. Holland, Inorg. Chem., 2003, 42, 1720-1725.

36 P. A. Adcock, F. R. Keene, R. S. Smythe and M. R. Snow, Inorg. Chem., 1984, 23, 2336-2343.

37 S. C. Rasmussen, S. E. Ronco, D. A. Mlsna, M. A. Billadeau, W. T. Pennington, J. W. Kolis and J. D. Petersen, Inorg. Chem., 1995, 34, 821-829.

38 E. Sondaz, A. Gourdon, J.-P. Launay and J. Bonvoisin, Inorg. Chim. Acta, 2001, 316, 79-88.

39 B. A. Johnson, H. Agarwala, T. A. White, E. Mijangos, S. Maji and S. Ott, Chem. - Eur. J., 2016, 22, 14870-14880.

40 C.-N. Tsai, M. M. Allard, R. L. Lord, D.-W. Luo, Y.-J. Chen, H. B. Schlegel and J. F. Endicott, Inorg. Chem., 2011, 50, 11965-11977.

41 M. Maestri, N. Armaroli, V. Balzani, E. C. Constable and A. M. W. Cargill Thompson, Inorg. Chem., 1995, 34, 27592767 .
42 Y. Kawanishi, N. Kitamura and S. Tazuke, Inorg. Chem., 1989, 28, 2968-2975.

43 A. W. King, L. Wang and J. J. Rack, Acc. Chem. Res., 2015, 48, 1115-1122.

44 B. J. Coe and S. J. Glenwright, Coord. Chem. Rev., 2000, 203, 5-80.

45 B. P. Sullivan, J. M. Calvert and T. J. Meyer, Inorg. Chem., 1980, 19, 1404-1407.

46 R. M. O’Donnell, R. N. Sampaio, G. Li, P. G. Johansson, C. L. Ward and G. J. Meyer, J. Am. Chem. Soc., 2016, 138, 3891-3903.

47 N. C. Fletcher and F. R. Keene, J. Chem. Soc., Dalton Trans., 1998, 2293-2302.

48 M. Furue, K. Maruyama, T. Oguni, M. Naiki and M. Kamachi, Inorg. Chem., 1992, 31, 3792-3795.

49 J. G. Calvert and J. N. Pitts, in Photochemistry, John Wiley and Sons, New York, 1966, pp. 780-786. 